\title{
The roles of oxygen non-stoichiometry on the electrochemical properties of oxide-based cathode materials
}

\author{
Jianming Zheng, Jie Xiao, and Ji-Guang Zhang* \\ Energy and Environment Directorate, Pacific Northwest National Laboratory, 902 Battelle \\ Boulevard, Richland, WA 99352, USA.
}

\begin{abstract}
Cathode materials with both high energy density and high power capability are in great demand to improve the performance of lithium ion batteries and expand the driving range of electric vehicles. Of particular interest are transition metal oxide-based cathodes. However, electrochemical performance of these cathode materials is very sensitive to the synthetic conditions and, particularly, the oxygen non-stoichiometry that is induced during high temperature synthesis and post-treatment. This review highlights the critical roles of oxygen nonstoichiometry in high-energy-density cathode materials including high voltage spinel $\mathrm{LiNi}_{0.5} \mathrm{Mn}_{1.5} \mathrm{O}_{4}$, Ni-rich layered $\mathrm{LiNi}_{\mathrm{x}} \mathrm{Mn}_{\mathrm{y}} \mathrm{Co}_{\mathrm{z}} \mathrm{O}_{2}$ (NMC, $\left.\mathrm{x}>0.5\right)$, and the Li-rich, Mn-rich layered cathode, with the aim to provide a fundamental understanding on the effects of the

\footnotetext{
* Corresponding author at: Energy and Environment Directorate, Pacific Northwest National Laboratory, 902 Battelle Boulevard, Richland, WA 99352, USA. Tel.: + 1509372 6515; fax: +1 5093752186.

Email address: jiguang.zhang @ pnnl.gov (J.-G. Zhang).
}

Abbreviations:

ALMO annealed $\mathrm{Li}_{2} \mathrm{MnO}_{3}$

EELS electron energy loss spectroscopy

EV electric vehicle

LIB lithium ion battery

LMR Li-rich Mn-rich

MLMO quenched $\mathrm{Li}_{2} \mathrm{MnO}_{3}$ milled with Super $\mathrm{P}$

$\mathrm{NMC} \quad \mathrm{LiNi}_{\mathrm{x}} \mathrm{Mn}_{\mathrm{y}} \mathrm{Co}_{\mathrm{z}} \mathrm{O}_{2}$

QLMO quenched $\mathrm{Li}_{2} \mathrm{MnO}_{3}$

TG thermogravimetric

TM transition metal
\end{abstract}


oxygen non-stoichiometry governing the crystalline structure, electrochemical performance, and thermal stability of different cathode materials. This review also offers perspectives and directions on how to best utilize oxygen non-stoichiometry in the future development of highenergy-density cathode materials for lithium ion batteries.

\section{Keywords}

Oxygen non-stoichiometry; Cathode materials; Ni-rich material; High voltage spinel; Li-rich Mn-rich; Lithium ion battery.

\section{Highlights}

- Oxygen non-stoichiometry, which is sensitive to the synthesis conditions, plays a critical role in manipulating the material crystal structure.

- Oxygen non-stoichiometry fundamentally affects the reaction pathway, electrochemical performances and thermal stability of cathode materials.

- The effects of oxygen non-stoichiometry should be carefully considered in the future development of high-energy-density cathode materials for lithium-ion batteries.

\section{Introduction}

Rechargeable lithium ion batteries (LIBs) have been widely used in consumer electronic devices and are quickly entering the electric vehicle (EV) and large-scale stationary energy storage market $[1,2]$. The state-of-the-art LIB system typically consists of a graphite anode, a nonaqueous electrolyte, and a lithium-containing cathode [3-5]. The cathode materials, whose available capacities are still smaller than that of graphite anodes, are under intensive exploration in order to further improve the energy density of the whole battery system. Traditional cathodes, 
such as $\mathrm{LiCoO}_{2}, \mathrm{LiMn}_{2} \mathrm{O}_{4}, \mathrm{LiFePO}_{4}$, and $\mathrm{LiNi}_{\mathrm{x}} \mathrm{Mn}_{\mathrm{y}} \mathrm{CO}_{\mathrm{z}} \mathrm{O}_{2}(\mathrm{NMC}$, $\mathrm{x}<0.5)$ have been commercially used as cathode materials for LIBs [1]. However, limitations in energy density, cycle life, cost and/or safety issues of these cathode materials still impede their mass application in long-range EV and large-scale grid applications $[6,7]$. In addition to these conventional cathode materials, three appealing cathode materials, that have attracted broad research interest and are being intensively investigated, are high voltage spinel $\mathrm{LiNi}_{0.5} \mathrm{Mn}_{1.5} \mathrm{O}_{4}, \mathrm{Ni}$-rich layeredstructure NMC with nickel content $\geq 0.5$, and the Li-rich Mn-rich (LMR) layered-structure cathode, because of their significant advantages in energy density and/or reduced cost.

Typical discharge voltage profiles of different cathode materials are shown in Fig. 1a, and their achievable energy densities are compared in Fig. 1b. Ranked in the top three are high voltage spinel, Ni-rich NMC, and LMR cathode materials, which have much higher energy density than traditional cathode materials, signifying a significant increase in the driving mileage of EVs [8-11]. The crystal structures of the three kinds of materials, i.e., $\mathrm{LiNi}_{0.5} \mathrm{Mn}_{1.5} \mathrm{O}_{4}$ spinels with the space group of ordered $\mathrm{P}_{3} 32$ and disordered Fd-3m, Ni-rich layered structure with R3m, and LMR with R-3m and C2/m monoclinic structures, are presented in Fig. 1c-f. High voltage spinel $\mathrm{LiNi}_{0.5} \mathrm{Mn}_{1.5} \mathrm{O}_{4}$ is a promising cathode candidate for LIBs because of its high operating voltage (ca. $4.7 \mathrm{~V}$ ), high energy density $\left(658 \mathrm{Wh} \mathrm{kg}^{-1}\right)$, low cost, and good rate capability [8, 12-14]. The three-dimensional tunnels for fast $\mathrm{Li}^{+}$ion transport enable the excellent rate capability, while the stable spinel crystalline structure guarantees a good long-term cycle life [15-17]. For layered-structure cathode materials, Ni-rich $\mathrm{LiNi}_{\mathrm{x}} \mathrm{Mn}_{\mathrm{y}} \mathrm{Co}_{\mathrm{z}} \mathrm{O}_{2}(\mathrm{x} \geq 0.5)$ cathode materials have been regarded as promising cathode alternatives due to their high achievable discharge capacity $\left(200 \sim 220 \mathrm{mAh} \mathrm{g}^{-1}\right)[9,11,18,19]$, representing a further enhancement in energy density $\left(\sim 800 \mathrm{Wh} \mathrm{kg}^{-1}\right)$ in comparison with traditional cathodes and the 
high voltage spinel. Furthermore, LMR layered-structure cathode materials with a composition of $x \mathrm{Li}_{2} \mathrm{MnO}_{3} \cdot(1-\mathrm{x}) \mathrm{LiMO}_{2}(\mathrm{M}=\mathrm{Ni}, \mathrm{Co}, \mathrm{Mn}$ or combinations $)$ or $\mathrm{Li}_{1+\mathrm{w}} \mathrm{Ni}_{\mathrm{x}} \mathrm{Mn}_{\mathrm{y}} \mathrm{Co}_{\mathrm{z}} \mathrm{O}_{2}$ deliver the highest energy density of ca. $900 \mathrm{Wh} \mathrm{kg}^{-1}$ among all known intercalation compound cathode materials [20-26].

Although the several cathode materials discussed above exhibit very attractive energy densities, their electrochemical performance is very sensitive to the synthesis method and postcalcination treatment conditions [27-29] whose influences cannot be detected immediately from X-ray diffraction patterns. The synthesis methods widely used for preparation of these cathode materials include solid-state reaction, co-precipitation method, sol-gel method, spray-dry method, and a hydrothermal method. All of these methods require a calcination step at high temperatures ranging from $700 \sim 1050^{\circ} \mathrm{C}$, which inevitably leads to oxygen loss at temperatures higher than ca. $700^{\circ} \mathrm{C}$ and the consequent formation of variable oxygen non-stoichiometry in the as-synthesized materials [30, 31]. In order to satisfy the charge balance, the average oxidation states of the transition metals (TMs) decrease in proportion to the oxygen non-stoichiometry, accompanied by changes in local crystal environments, which adversely or beneficially affect the electrochemical performance of the cathode materials [31-33]. In principle, the degree of oxygen non-stoichiometry changes as a function of calcination temperature and oxygen partial pressure $p \mathrm{O}_{2}[31,34]$. Oxygen can be recaptured into the material crystal during a cooling process at ca. $600 \sim 700^{\circ} \mathrm{C}$ [15], and this process is dependent on cooling method [35]. In addition, the degree of oxygen non-stoichiometry is also dependent on the material's crystal structure and composition [30], and should be carefully controlled during the development of different kinds of cathode materials in order to maximize their electrochemical performance. The roles of oxygen nonstoichiometry have been well investigated in the cathode materials for solid oxide fuel cells [ 34 , 
$36,37]$, but the important role of oxygen non-stoichiometry in the investigation of high-energydensity cathode materials for LIBs is still not well recognized.

In this review, we focus on discussion regarding the roles of oxygen non-stoichiometry on the crystalline structure and electrochemical performance of the three high-energy-density cathode materials: high voltage spinel $\mathrm{LiNi}_{0.5} \mathrm{Mn}_{1.5} \mathrm{O}_{4}, \mathrm{Ni}$-rich $\mathrm{NMC}$ cathode material, and LMR cathode material. This review aims to provide a full understanding on the positive and negative effects of the oxygen non-stoichiometry governing the electrochemical performance of different cathode materials. The effects of oxygen non-stoichiometry during electrochemical activation and oxygen loss during thermal reactions are systematically analyzed. Finally, perspectives and directions on how to fully utilize the advantages of oxygen non-stoichiometry to further improve the performance of high-energy-density cathode materials for LIBs will be discussed.

\section{Discussion}

\subsection{Oxygen non-stoichiometry in spinel cathodes}

The effects of oxygen non-stoichiometry in the traditional $\mathrm{LiMn}_{2} \mathrm{O}_{4}$ spinel have been well studied before [38-42]. In case of $\mathrm{LiMn}_{2} \mathrm{O}_{4}$, oxygen deficiency is considered as a trigger of structural degradation and capacity fading due to the dominating $\mathrm{Mn}^{3+}$ and its damaging JahnTeller distortion effects. However, oxygen non-stoichiometry shows opposite effect on $\mathrm{LiNi}_{0.5} \mathrm{Mn}_{1.5} \mathrm{O}_{4}$. This is because $\mathrm{LiNi}_{0.5} \mathrm{Mn}_{1.5} \mathrm{O}_{4}$ mainly operates with $\mathrm{Ni}^{2+/ 4+}$ redox couples during charge/discharge processes, whereas the structural damage caused by $\mathrm{Mn}^{3+}$-induced JahnTeller distortions is very limited because of the minor content of $\mathrm{Mn}^{3+}$. Here, we focus on discussing the roles of oxygen non-stoichiometry in high voltage spinel $\mathrm{LiNi}_{0.5} \mathrm{Mn}_{1.5} \mathrm{O}_{4}$ from the relationship of synthesis-structure-electrochemical properties point of view. $\mathrm{LiNi}_{0.5} \mathrm{Mn}_{1.5} \mathrm{O}_{4}$ 
exhibits two types of phase structures, i.e., ordered $\mathrm{P}_{3} 32$ and disordered Fd-3m [43-45].

Ordered $\mathrm{LiNi}_{0.5} \mathrm{Mn}_{1.5} \mathrm{O}_{4}$ with space group $\mathrm{P}_{3} 32$ has $\mathrm{Li}$ at tetrahedral $8 \mathrm{a}$ sites, $\mathrm{Ni}$ at octahedral $4 \mathrm{~b}$ sites and Mn at octahedral 12d sites (Fig. 1c). The cubic close-packed $\mathrm{O}$ ions are located at 8c and $24 \mathrm{e}$ sites. In this ordered $\mathrm{Ni} / \mathrm{Mn}$ arrangement, all $\mathrm{Ni}^{2+}$ ions are coordinated with the six nearest neighboring $\mathrm{Mn}^{4+}$ atoms in the crystal lattice. For the disordered $\mathrm{LiNi}_{0.5} \mathrm{Mn}_{1.5} \mathrm{O}_{4}$ with space group $\mathrm{Fd}-3 \mathrm{~m}$ phase, $\mathrm{Ni}$ and $\mathrm{Mn}$ distribute randomly in the octahedral $16 \mathrm{~d}$ sites in a ratio of 1:3, while Li and $\mathrm{O}$ are located in 8a and 32e sites, respectively (Fig. 1d).

Formation of ordered or disordered spinel phase is closely related to the oxygen nonstoichiometry that is created during preparation of the material. Recently, Chen et al. employed density functional theory (DFT) first-principles calculation to investigate the origin of the Ni/Mn ordering in $\mathrm{LiNi}_{0.5} \mathrm{Mn}_{1.5} \mathrm{O}_{4}$ [45]. Their calculation results demonstrate that without oxygen vacancies, the formation of ordered $\mathrm{Ni}^{2+}$ and $\mathrm{Mn}^{4+}$ ions (1:3 ratio) is energetically favorable in comparison with the disordered $\mathrm{Ni}^{3+}$ and $\mathrm{Mn}^{3+}$ ions that are formed owing to $\mathrm{Ni}$ aggregation in the ordered $\mathrm{P}_{3} 32$ phase (Fig. 2a). However, at elevated temperature, increased ionic mobility gives rise to the appearance of $\mathrm{Ni}$ aggregated structure as an instantaneous state (Fig. 2b). This $\mathrm{Ni}$ aggregated structure is unstable and susceptible to oxygen loss. In the presence of oxygen vacancies, the energy gap between the $\mathrm{P} 4332$ super cell and the $\mathrm{Ni}$ aggregated structure is greatly decreased (Fig. 2c, d), resulting in the formation of oxygen-deficient $\mathrm{LiNi}_{0.5} \mathrm{Mn}_{1.5} \mathrm{O}_{4-\mathrm{d}}$ with disordered Ni/Mn distribution. This is how the Ni/Mn disorder is induced and stabilized in the presence of oxygen vacancies.

Calcination temperature has significant effects on the content of oxygen non-stoichiometry in the $\mathrm{LiNi}_{0.5} \mathrm{Mn}_{1.5} \mathrm{O}_{4}$, because higher calcination temperature readily leads to more oxygen loss. Kunduraci et al. systematically studied the correlations between material properties (electrical 
conductivity, lattice constant, morphology) and the electrochemical performance of $\mathrm{LiNi}_{0.5} \mathrm{Mn}_{1.5} \mathrm{O}_{4}$ prepared at different temperatures $[15,46]$. Their results show that the onset temperature for oxygen loss is $712^{\circ} \mathrm{C}$, where the $\mathrm{LiNi}_{0.5} \mathrm{Mn}_{1.5} \mathrm{O}_{4}$ undergoes a thermally driven ordered-to-disordered phase transition, as confirmed with Fourier transform infrared spectroscopy (FTIR) measurements (Fig. 3a, b) [15, 46]. Therefore, $700^{\circ} \mathrm{C}$ is a critical temperature for the preparation of $\mathrm{LiNi}_{0.5} \mathrm{Mn}_{1.5} \mathrm{O}_{4}$ : ordered spinel is produced at $700^{\circ} \mathrm{C}$, while further increase of temperature produces disordered spinels with different oxygen nonstoichiometry. Accompanying the oxygen non-stoichiometry is the creation of lattice $\mathrm{Mn}^{3+}$ in disordered spinel to satisfy the charge neutrality, which is responsible for the increase of lattice parameters (Fig. 3c) owing to the larger ionic radius of $\mathrm{Mn}^{3+}(0.66 \AA)$ as compared to $\mathrm{Mn}^{4+}(0.54$ $\AA$ A). Thus, the degree of oxygen non-stoichiometry could be evaluated through determining the lattice parameters of the spinel phase [47]. The additional electron hopping paths between $\mathrm{Mn}^{3+} / \mathrm{Mn}^{4+}$ cations in the disordered spinel also leads to a significant increase in the electrical conductivity. The electronic conductivity of disordered (Fd-3m) spinel phase is up to 2.5 orders of magnitude higher than that of the cation ordered $\left(\mathrm{P}_{3}{ }_{3} 32\right)$ spinel phase (Fig. $\left.3 \mathrm{c}\right)$. The disordered spinel shows a minimum energy barrier of $0.32 \mathrm{eV}$ for conduction, which is much lower than the $0.45 \mathrm{eV}$ for fully ordered spinel (Fig. 3d).

Due to the structural difference caused by oxygen non-stoichiometry, the ordered and disordered $\mathrm{LiNi}_{0.5} \mathrm{Mn}_{1.5} \mathrm{O}_{4}$ behave quite differently during the electrochemical charge/discharge processes (Fig. 3e). The disordered $\mathrm{LiNi}_{0.5} \mathrm{Mn}_{1.5} \mathrm{O}_{4}$ exhibits a minor voltage plateau at ca. $4.0 \mathrm{~V}$, besides the two major voltage plateaus in the $\sim 4.7 \mathrm{~V}$ region that is related to the $\mathrm{Ni}^{2+} \leftrightarrow \mathrm{Ni}^{3+} \leftrightarrow \mathrm{Ni}^{4+}$ redox reactions. The existence of the $4.0 \mathrm{~V}$ plateau is a signature of the presence of $\mathrm{Mn}^{3+}$, and the percentage of the $\mathrm{Mn}^{3+}$ as characterized relative to the overall capacity 
could be used to quantify the oxygen non-stoichiometry and differentiate the ordered and disordered $\mathrm{LiNi}_{0.5} \mathrm{Mn}_{1.5} \mathrm{O}_{4}$. Another difference between ordered and disordered spinel phases is observed in the $4.7 \mathrm{~V}$ voltage plateau. Disordered spinel shows an obvious voltage step at $\mathrm{x}=0.5$ in $\mathrm{Li}_{\mathrm{x}} \mathrm{Ni}_{0.5} \mathrm{Mn}_{1.5} \mathrm{O}_{4}$, while a negligible voltage step is observed for the ordered spinel. This is ascribed to the incommensurateness between the preferred Li/vacancy ordering and the $\mathrm{Ni} / \mathrm{Mn}$ configuration in ordered $\mathrm{P} 4332$ spinel $\mathrm{Li}_{\mathrm{x}} \mathrm{Ni}_{0.5} \mathrm{Mn}_{1.5} \mathrm{O}_{4}$ with $\mathrm{x}=0.5$, according to the computational simulations using first-principles energy calculations [44, 48]. Moreover, disordered spinel $\left(800^{\circ} \mathrm{C}\right)$ exhibits superior capacity retention as compared to the ordered spinel $\left(700^{\circ} \mathrm{C}\right)(\mathrm{Fig} .3 \mathrm{f})$, due to the higher electrical conductivity and lithium ion diffusivity. Therefore, oxygen non-stoichiometry is a key factor governing the structure and electrochemical performance of high voltage spinel $\mathrm{LiNi}_{0.5} \mathrm{Mn}_{1.5} \mathrm{O}_{4}$ cathode materials.

Significant effort has been made to tune the content of oxygen non-stoichiometry in $\mathrm{LiNi}_{0.5} \mathrm{Mn}_{1.5} \mathrm{O}_{4}$ in order to achieve improved electrochemical performance. Jin et al. demonstrated a significant improvement of rate capability in $\mathrm{LiNi}_{0.5} \mathrm{Mn}_{1.5} \mathrm{O}_{4-\delta}$ with the aid of increased oxygen non-stoichiometry [49]. Various oxygen non-stoichiometries were achieved through calcining $\mathrm{LiNi}_{0.5} \mathrm{Mn}_{1.5} \mathrm{O}_{4}$ above the onset temperature of oxygen loss at $700^{\circ} \mathrm{C}$, i.e., $700^{\circ} \mathrm{C}, 730^{\circ} \mathrm{C}$, and $750^{\circ} \mathrm{C}$. The materials containing higher oxygen non-stoichiometry $(\delta=0.025$ $\left.\left(730^{\circ} \mathrm{C}\right), 0.033\left(750^{\circ} \mathrm{C}\right)\right)$ have the ability to deliver discharge capacities higher than 115 and 110 $\mathrm{mAh} \mathrm{g}^{-1}$ at $5 \mathrm{C}$ and $7 \mathrm{C}$ rates, much higher than that achieved by one with $\delta=0.015\left(700^{\circ} \mathrm{C}\right)$. Recently, Liu et al. reported the morphological evolution of $\mathrm{LiNi}_{0.5} \mathrm{Mn}_{1.5} \mathrm{O}_{4}$ spinels prepared at temperatures ranging from $700^{\circ} \mathrm{C}$ to $1000^{\circ} \mathrm{C}[50]$. The spinel materials prepared at higher calcination temperature outperform those prepared at relatively lower calcination temperatures during long-term cycling. Besides the morphological effects, the greater oxygen non- 
stoichiometry in the high temperature spinel materials, though not discussed, is believed to play an important role in improving the electrical conduction and thus enabling the long-term cycle life. However, high calcination temperature $\left(>900^{\circ} \mathrm{C}\right)$ results in too much oxygen loss from spinel accompanied by the formation of a secondary phase that could be assigned to rock-salt impurity $\left(\mathrm{NiO}_{x}, \mathrm{Li}_{x} \mathrm{Ni}_{1-\mathrm{x}} \mathrm{O},(\mathrm{LiNiMn})_{\mathrm{x}} \mathrm{O}\right)[51,52]$, which reduces the reversible capacity as a consequence.

Several groups investigated the effects of oxygen non-stoichiometry on the crystal structure and the electrochemical performance of $\mathrm{LiNi}_{0.5} \mathrm{Mn}_{1.5} \mathrm{O}_{4}$ spinel by comparing ordered and disordered phase $[32,43,53]$. Although the oxygen loss at temperatures above $700^{\circ} \mathrm{C}$ induces the transition from ordered to disordered spinel phase [15], this process is reversed during the cooling process $[46,49,54]$. Disordered spinel with oxygen deficiency could retake some oxygen back into the crystal structure at ca. $700^{\circ} \mathrm{C}$ and convert back to ordered phase. Typically, the non-stoichiometric $\mathrm{LiNi}_{0.5} \mathrm{Mn}_{1.5} \mathrm{O}_{4}$ is prepared at $900^{\circ} \mathrm{C}$, which is further reannealed at $700^{\circ} \mathrm{C}$ for $48 \mathrm{~h}$ to produce the ordered spinel phase [43]. It is well recognized that, as compared to the $\mathrm{P}_{3} 32$ disordered spinel, the Fd-3m disordered spinel with oxygen non-stoichiometry shows better electrochemical behavior not only at room temperature but also at high temperature $\left(55^{\circ} \mathrm{C}\right)$, especially at high $\mathrm{C}$ rates. Nevertheless, there is a different view from Ma et al. emphasizing that high intrinsic rate capability could be obtained for ordered $\mathrm{LiNi}_{0.5} \mathrm{Mn}_{1.5} \mathrm{O}_{4}$ with an careful optimization of cell components and electrode construction [55], which, however, was not further compared with that of any disordered $\mathrm{LiNi}_{0.5} \mathrm{Mn}_{1.5} \mathrm{O}_{4}$ under exactly the same testing conditions.

Xiao et al. further correlated residual $\mathrm{Mn}^{3+}$ with disordered phase in spinel using oxygen non-stoichiometry as the bridge [32]. In their work, the concentration of $\mathrm{Mn}^{3+}$ ions in the lattice 
was manipulated by combining post-synthesis annealing with partial substitution of $\mathrm{Ni}^{2+}$ by $\mathrm{Cr}^{3+}$; neither approach noticeably affects the sample morphology or surface area. Ordered $\mathrm{LiNi}_{0.5} \mathrm{Mn}_{1.5} \mathrm{O}_{4}$ (reannealed at $700^{\circ} \mathrm{C}$ ) was systematically compared with disordered $\mathrm{LiNi}_{0.5} \mathrm{Mn}_{1.5} \mathrm{O}_{4}$ (as-prepared at $900^{\circ} \mathrm{C}$ ) from the lattice $\mathrm{Mn}^{3+}$ concentration point of view. The amount of $\mathrm{Mn}^{3+}$ ions changes simultaneously with that of disordered phase caused by randomization of $\mathrm{Mn}^{4+}$ and $\mathrm{Ni}^{2+}$ occupancies in the octahedral sites. Their computational simulations further indicate that the $\mathrm{Mn}^{3+}$ formation in $\mathrm{LiNi}_{0.5} \mathrm{Mn}_{1.5} \mathrm{O}_{4}$ spinel promotes $\mathrm{Ni}-\mathrm{Mn}$ site disorder that facilitates $\mathrm{Li}^{+}$ion transport, especially in the high $\mathrm{C}$-rate regimes. More importantly, the spinels with appropriate $\mathrm{Mn}^{3+}$ contents (the disordered phase) demonstrate improved electrochemical performance as compared to the reannealed ordered spinel, suggesting that careful control of the amount of $\mathrm{Mn}^{3+}$ ions is the key for development of high performance $\mathrm{LiNi}_{0.5} \mathrm{Mn}_{1.5} \mathrm{O}_{4}$ spinel.

Another approach to tune the ordered/disordered phase is to precisely control the cooling rate immediately after high temperature calcination. If faster cooling is adopted, the dwell time at the oxygen restoration temperature $\left(\sim 700^{\circ} \mathrm{C}\right)$ is not long enough to recover the oxygen deficiency because of the slow reaction kinetics. The spinel structure is thus dominated by disordered phase with random $\mathrm{Ni} / \mathrm{Mn}$ distribution. On the other hand, if the cooling is slow enough, the $\mathrm{LiNi}_{0.5} \mathrm{Mn}_{1.5} \mathrm{O}_{4}$ could recover from the oxygen non-stoichiometry and simultaneously the $\mathrm{Ni} / \mathrm{Mn}$ ions would redistribute to reach their ordered ground state, i.e., the well-ordered $\mathrm{P} 4332$ phase [45]. Zheng et al. precisely adjusted the degree of oxygen non-stoichiometry (or $\mathrm{Mn}^{3+}$ content) in spinels by using different cooling rates [35]. It was revealed that during slow cooling $\left(\leq{ }^{\circ} \mathrm{C} \mathrm{min}^{-}\right.$ ${ }^{1}$ ), oxygen non-stoichiometry is mitigated by oxygen intake, and thus the residual $\mathrm{Mn}^{3+}$ amount is also decreased in spinel to restore charge balance (Fig. 4a). A superlattice pattern appears 
when the cooling rate is below $1{ }^{\circ} \mathrm{C} \min ^{-1}$ (Fig. $4 \mathrm{~b}, \mathrm{c}$ ). The presence of an appropriate amount of oxygen non-stoichiometry and/or $\mathrm{Mn}^{3+}$ is critical to facilitate $\mathrm{Li}^{+}$ion transport in the crystal structure, which enhances the electrochemical properties of $\mathrm{LiNi}_{0.5} \mathrm{Mn}_{1.5} \mathrm{O}_{4} . \mathrm{LiNi}_{0.5} \mathrm{Mn}_{1.5} \mathrm{O}_{4}$ with $10.8 \% \mathrm{Mn}^{3+}$ shows high rate capability $\left(96 \mathrm{mAh} \mathrm{g}^{-1}\right.$ at $\left.10 \mathrm{C}\right)$ and excellent cycling performance with $94.8 \%$ capacity retention after 300 cycles (Fig. 4d). In-situ X-ray diffraction (XRD) demonstrates that the presence of disordered phase fundamentally changes the phase transition path during electrochemical charge/discharge processes (Fig. 4e, f). The more nonstoichiometry $/ \mathrm{Mn}^{3+}$, the wider the solid-solution range would be during the charge process. The change of the first two-phase transition into a solid-solution reaction apparently benefits $\mathrm{Li}^{+}$ion transport by reducing the phase boundaries that $\mathrm{Li}^{+}$ions have to overcome. The variation of oxygen non-stoichiometry and/or $\mathrm{Mn}^{3+}$ content is considered to be the primary reason for the differences in the phase transitions of high voltage $\mathrm{LiNi}_{0.5} \mathrm{Mn}_{1.5} \mathrm{O}_{4}$ spinel. The beneficial effects of non-stoichiometry/ $\mathrm{Mn}^{3+}$ have been further confirmed in a full-cell configuration using $\mathrm{Li}_{4} \mathrm{Ti}_{5} \mathrm{O}_{12}$ as anode [56].

Due to the large amount of $\mathrm{Li}_{\mathrm{x}} \mathrm{Ni}_{\mathrm{y}} \mathrm{O}$ impurity, quenched spinel delivers the lowest initial discharge capacity $\left(78 \mathrm{mAh} \mathrm{g}^{-1}\right)$ even at a low current density of $0.1 \mathrm{C}$ (Fig. 4d). The length of the $4.7 \mathrm{~V}$ voltage plateau decreases, while the voltage plateau at $4.0 \mathrm{~V}$ becomes dominant during charge/discharge processes, suggesting the formation of a Ni-deficient $\mathrm{LiNi}_{\mathrm{x}} \mathrm{Mn}_{2-\mathrm{x}} \mathrm{O}_{4}$ with $\mathrm{Ni}$ rich rock-salt impurity phase. Quenching is widely used during preparation of LMR cathode materials $\mathrm{xLi}_{2} \mathrm{MnO}_{3} \cdot(1-\mathrm{x}) \mathrm{LiMO}_{2}(\mathrm{M}=\mathrm{Ni}, \mathrm{Co}, \mathrm{Mn})$, because a significant amount of oxygen non-stoichiometry could facilitate activation of the $\mathrm{Li}_{2} \mathrm{MnO}_{3}$ component, which will be further discussed in detail later. However, quenching brings negative effects to spinel performance because such a high content of impurity reduces the capacity of the full cathode. Even with such 
a complicated effect, quenching treatment has been occasionally used as an easy way to investigate the degree of oxygen non-stoichiometry at certain temperatures, because quenching can preserve the specific structural characteristics at the calcination temperature and avoid the influence of changes upon cooling that are associated with oxygen uptake [47, 51].

Pasero et al. [51] and Wang et al. [47], respectively, investigated the oxygen nonstoichiometry phase compositions in spinels prepared at different temperatures by quenching the samples in liquid nitrogen at the end of heating. Although the oxygen non-stoichiometry estimated by different methods is different, it follows the same trend that higher calcination temperature leads to more oxygen non-stoichiometry. Wang et al. demonstrated that the samples quenched from higher temperature have larger lattice parameters and more TM ions on the tetrahedral sites (Fig. 5a) [47]. The increase of lattice parameters is because of more reduction of $\mathrm{Mn}$ from $\mathrm{Mn}^{4+}$ to $\mathrm{Mn}^{3+}$ associated with greater oxygen non-stoichiometry. The oxygen nonstoichiometry is estimated to be $\delta=0.002,0.066,0.089$, and 0.121 for samples quenched from $650^{\circ} \mathrm{C}, 800^{\circ} \mathrm{C}, 850^{\circ} \mathrm{C}$, and $900^{\circ} \mathrm{C}$, respectively, on the basis of TG analysis (Fig. $5 \mathrm{~b}, \mathrm{c}$ ). Apparently, the samples with more oxygen non-stoichiometry exhibit lower capacity with increasing length of the $4.0 \mathrm{~V}$ voltage plateau because of higher content of rock-salt impurity phase (Fig. 5d).

Despite its lower electrical conductivity, the ordered spinel is still an appealing cathode candidate because of its higher operating voltage and larger discharge capacity as compared to the disordered counterpart. Moreover, stability of the spinel framework could be improved in materials that are not highly involved with the $\mathrm{Mn}^{3+/ 4+}$ redox couple, due to mitigation of the structural damage caused by $\mathrm{Mn}^{3+}$-induced Jahn-Teller distortions during cycling. Further in full cells in which graphite is used as the anode, the content of $\mathrm{Mn}^{3+}$ needs to be carefully controlled 
in order to reduce the potential $\mathrm{Mn}^{2+}$ formation which destroys the graphite lattice structure. Formation of ordered $\mathrm{LiNi}_{0.5} \mathrm{Mn}_{1.5} \mathrm{O}_{4}$ spinels can be manipulated by the sintering conditions and/or controlling the reannealing gas atmosphere during material preparation $[57,58]$.

Replacing air with $\mathrm{O}_{2}$ atmosphere during material sintering can significantly reduce the oxygen non-stoichiometry and increase the ordered phase in $\mathrm{LiNi}_{0.5} \mathrm{Mn}_{1.5} \mathrm{O}_{4}$ spinel $[51,57,58]$. However, conflicting results have been reported by different groups. Li et al. reported that a reannealing treatment in $\mathrm{O}_{2}$ at $500^{\circ} \mathrm{C}$ for $30 \mathrm{~h}$ could not only reduce the $\mathrm{Mn}^{3+}$ content, but also significantly increase the discharge capacity and enhance the rate performance in comparison with the untreated material [57]. On the contrary, Wang et al. prepared $\mathrm{LiNi}_{0.5} \mathrm{Mn}_{1.5} \mathrm{O}_{4}$ in an $\mathrm{O}_{2}$ gas atmosphere at $800^{\circ} \mathrm{C}$ for $20 \mathrm{~h}$ and compared its performance to that of the material prepared in air [58]. They found that the material calcined in air shows superior specific capacity, cycling stability, and rate capability as compared with the material calcined in an $\mathrm{O}_{2}$ atmosphere, which is expected to be oxygen-deficiency free and $\mathrm{Mn}^{3+}$ free. As discussed above, a trace amount of $\mathrm{Mn}^{3+}$ ions in the spinel material calcined in air is indispensable to ensure the better rate capability and cycle life by improving the electronic/ionic conductivities of the $\operatorname{LiNi}_{0.5} \mathrm{Mn}_{1.5} \mathrm{O}_{4}$ spinel. This controversy may have originated from the difference in the calcination temperature, material synthesis method, and the particle morphology of the prepared material. It is worth mentioning that the particle morphology indeed shows significant effects on the electrochemical performance of the $\mathrm{LiNi}_{0.5} \mathrm{Mn}_{1.5} \mathrm{O}_{4}$ spinel material $[50,59,60]$. Zhang et al. prepared $\mathrm{LiNi}_{0.5} \mathrm{Mn}_{1.5} \mathrm{O}_{4}$ porous nanorods with high purity ordered $\mathrm{P} 4_{3} 32$ phase by sintering the precursor at $700^{\circ} \mathrm{C}$ for $6 \mathrm{~h}$ in air [60]. The $\mathrm{LiNi}_{0.5} \mathrm{Mn}_{1.5} \mathrm{O}_{4}$ porous nanorods offer excellent high-rate capability along with good long-term cyclability, delivering a discharge capacity of $109 \mathrm{mAh} \mathrm{g}^{-1}$ at 20C and capacity retention of 99\% up to 300 cycles at 5C. This excellent electrochemical 
performance could be attributed to the enhanced electrical conductivity derived from the nanorod hierarchical structure. From practical application point of view, however, $\mathrm{LiNi}_{0.5} \mathrm{Mn}_{1.5} \mathrm{O}_{4}$ does not have to go to nanosize to achieve the aforementioned electrochemical properties since tailoring the oxygen non-stoichiometry has the same effects.

Reannealing $\mathrm{LiNi}_{0.5} \mathrm{Mn}_{1.5} \mathrm{O}_{4}$ at an oxygen-uptake temperature $\left(600 \sim 700^{\circ} \mathrm{C}\right)$ is a common approach to control the oxygen non-stoichiometry and manipulate the degree of disorder in TM ion arrangements. However, the dwell time at the annealing temperature varies greatly in different articles, ranging from a few hours to several days $[15,43,53,54]$. To identify the effects of annealing time, Kim et al. systematically investigated the evolution of $\mathrm{Ni}$ and $\mathrm{Mn}$ ordering in $\mathrm{LiNi}_{0.5} \mathrm{Mn}_{1.5} \mathrm{O}_{4}$ spinel samples by annealing them at $700^{\circ} \mathrm{C}$ in air for various dwell times, in order to maximize the battery performance [61]. With increasing annealing time at $700^{\circ} \mathrm{C}$, the amount of ordered phase and the size of $\mathrm{Ni} / \mathrm{Mn}$ ordered domains in $\mathrm{LiNi}_{0.5} \mathrm{Mn}_{1.5} \mathrm{O}_{4}$ spinel increases, concomitant with reduced amount of secondary phases (Fig. 6a). The amount of secondary phases in $\mathrm{LiNi}_{0.5} \mathrm{Mn}_{1.5} \mathrm{O}_{4}$ decreases greatly from $10.5 \%$ before annealing to $4.7 \%$ after $2 \mathrm{~h}$ annealing. Thanks to the decrease in secondary phase content and increase of ordered phase, the gravimetric capacity of $\mathrm{LiNi}_{0.5} \mathrm{Mn}_{1.5} \mathrm{O}_{4}$ increases from 123 to $130 \mathrm{mAh} \mathrm{g}^{-1}$, and the voltage profile featuring the transition from disordered to ordered spinel is observed after annealing at $700^{\circ} \mathrm{C}$ (Fig. 6b). However, a decrease of oxygen non-stoichiometry in $\mathrm{LiNi}_{0.5} \mathrm{Mn}_{1.5} \mathrm{O}_{4}$ impairs its cycle life in half-cells, which degrades as a function of annealing time from $92.9 \%$ (before annealing) to $82.1 \%$ (48 $\mathrm{h}$ annealing) after $100 \mathrm{cycles}$ at $\mathrm{C} / 5 \mathrm{rate}$ (Fig. 6c). Moreover, the $\mathrm{LiNi}_{0.5} \mathrm{Mn}_{1.5} \mathrm{O}_{4}$ shows inferior rate capability after annealing at $700^{\circ} \mathrm{C}$ for $48 \mathrm{~h}$ (Fig. $6 \mathrm{~d}$ ). The optimal battery performance (capacity, cycle life, and rate capability) for the $\mathrm{LiNi}_{0.5} \mathrm{Mn}_{1.5} \mathrm{O}_{4}$ is found after annealing at $700^{\circ} \mathrm{C}$ for $2 \mathrm{~h}$, from a combination of the advantages of both disordered 
and ordered spinels: better spinel-phase purity (higher initial capacity) from ordered phase and better cycle life / rate capability from disordered phase.

\subsection{Oxygen non-stoichiometry in Ni-rich layered-structure cathodes}

Ni-rich $\mathrm{LiNi}_{x} \mathrm{Mn}_{\mathrm{y}} \mathrm{Co}_{\mathrm{z}} \mathrm{O}_{2}(\mathrm{NMC}, \mathrm{x} \geq 0.5)$ belongs to a layered structure with space group R$3 \mathrm{~m}$ (Fig. 1e), which is analogous to $\mathrm{LiCoO}_{2}$. Among the TM ions involved with the $\mathrm{LiNi}_{\mathrm{X}} \mathrm{Mn}_{\mathrm{y}} \mathrm{Co}_{\mathrm{z}} \mathrm{O}_{2}$ cathode compositions, $\mathrm{Ni}$ is able to operate with both the $\mathrm{Ni}^{2+/ 3+}$ and $\mathrm{Ni}^{3+/ 4+}$ couples without a drastic variation in voltage during charge-discharge cycling. Ni can also be oxidized to $\mathrm{Ni}^{4+}$ without severely oxidizing the $\mathrm{O}^{2-}$ ions to oxygen, unlike the $\mathrm{Co}^{3+/ 4+}$ couple $[62$, 63]. Therefore, Ni-rich NMC cathodes offer high discharge capacities of $200-220 \mathrm{~mA} \mathrm{~h} \mathrm{~g}^{-1}$ at an acceptable charge cut-off voltage, typically $4.3 \sim 4.5 \mathrm{~V}$. However, there are still some technical challenges hindering the large-scale application of Ni-rich cathode materials $[9,11]$. One of them is the $\mathrm{Li} / \mathrm{Ni}$ cation disorder arising from the difficulty in maintaining all the $\mathrm{Ni}$ in $3+$ valence state. The presence of $\mathrm{Ni}^{2+}$ in $\mathrm{Li}$ layer blocks the lithium ion diffusion path and deteriorates the material's electrochemical performance [64, 65]. Despite the similar ionic radii of $\mathrm{Ni}^{2+}(0.69 \AA)$ and $\mathrm{Li}^{+}(0.76 \AA)$, the formation of $\mathrm{Li} / \mathrm{Ni}$ cation disorder is closely related to the variation of oxygen stoichiometry during synthesis at high temperature. As compared to Co- and Mn-based cathode materials, Ni-based cathode materials are more susceptible to oxygen loss accompanied by a reduction of $\mathrm{Ni}$ from $\mathrm{Ni}^{3+}$ to $\mathrm{Ni}^{2+}$, consequently leading to interlayer mixing $[65,66]$. Therefore, controlling the oxygen non-stoichiometry is important in the development of high performance Ni-rich NMC cathode materials.

Calcination temperature [67], calcination atmosphere $\left(\mathrm{O}_{2}\right.$, air, etc.) $[68,69]$, and heating/cooling rates [70] are important factors governing the oxygen non-stoichiometry in Nirich NMC cathode materials. Idris et al. did a detailed investigation on the effects of oxygen non- 
stoichiometry and interlayer $\mathrm{Li} / \mathrm{Ni}$ disorder on the performance of layered $\mathrm{Ni}$-rich

$\mathrm{LiNi}_{0.8} \mathrm{Mn}_{0.1} \mathrm{Co}_{0.1} \mathrm{O}_{2-\delta}[31]$. Even though the material could not provide high discharge capacity, this study provides useful information on the relationship between calcination temperature/atmosphere and the oxygen non-stoichiometry as well as the consequent interlayer disorder in $\mathrm{LiNi}_{0.8} \mathrm{Mn}_{0.1} \mathrm{Co}_{0.1} \mathrm{O}_{2-\delta}$. Increasing oxygen loss is observed to occur at temperatures higher than ca. $700^{\circ} \mathrm{C}$ in $\mathrm{N}_{2}$, ca. $800^{\circ} \mathrm{C}$ in air, and ca. $900^{\circ} \mathrm{C}$ in pure $\mathrm{O}_{2}$ (Fig. 7 a). The material prepared in $\mathrm{O}_{2}$ shows the least oxygen non-stoichiometry, followed by the material prepared in air and then the one prepared in $\mathrm{N}_{2}$ (Fig. 7b). The direct consequence of oxygen nonstoichiometry is the increased formation of $\mathrm{Li} / \mathrm{Ni}$ cation disorder, due to the increased content of $\mathrm{Ni}^{2+}$, which has similar ionic radius to $\mathrm{Li}^{+}[71]$, resulting in inferior electrochemical performance of the prepared materials. In contrast with the case in high voltage spinel, oxygen nonstoichiometry is deleterious to the performance of Ni-rich NMC cathode materials, and therefore an oxidative condition is preferred for the synthesis of Ni-rich NMC materials.

Later, Bi et al. further investigated the influence of oxygen non-stoichiometry on the characteristics of $\mathrm{LiNi}_{0.8} \mathrm{Mn}_{0.1} \mathrm{Co}_{0.1} \mathrm{O}_{2}$ cathode material by tuning the $\mathrm{O}_{2} / \mathrm{N}_{2}$ ratio in the calcination atmosphere [69]. Among the investigated samples, the degree of Li/Ni disorder in the bulk and the thickness of an auto-generated layer on the material surface evolve concurrently with the increase of oxygen non-stoichiometry in $\mathrm{LiNi}_{0.8} \mathrm{Mn}_{0.1} \mathrm{Co}_{0.1} \mathrm{O}_{2-\delta}$ materials (Fig. 8). A lower oxygen partial pressure $\left(p \mathrm{O}_{2}\right)$ in the calcination atmosphere leads to increased formation of oxygen non-stoichiometry in the $\mathrm{LiNi}_{0.8} \mathrm{Mn}_{0.1} \mathrm{Co}_{0.1} \mathrm{O}_{2-\delta}$ materials (Fig. 8b). The higher content of oxygen non-stoichiometry leads to the generation of more $\mathrm{Li} / \mathrm{Ni}$ cation disorder and a decomposed product on the particle surface (Fig. 8c, d), drastically degrading the electrochemical performance of the material due to the severe electrode polarization. Thanks to 
its structural integrity, the material with the least oxygen non-stoichiometry (prepared in pure $\mathrm{O}_{2}$ ) exhibits the highest discharge capacity (193 $\mathrm{mAh} \mathrm{g}^{-1}$ at $\left.0.1 \mathrm{C}\right)$, the best rate capability (160 $\mathrm{mAh}$ $\mathrm{g}^{-1}$ at $\left.5 \mathrm{C}\right)$, and the most stable cyclability ( $89.9 \%$ at $200^{\text {th }}$ cycle) (Fig. 8e). Their results clearly indicate that suppressing the oxygen non-stoichiometry is the key to achieve improved electrochemical performance of Ni-rich cathode materials.

Lee et al. investigated the effects of calcination temperature and atmosphere on the structural and electrochemical performance of Ni-rich $\mathrm{LiNi}_{0.6} \mathrm{Mn}_{0.2} \mathrm{Co}_{0.2} \mathrm{O}_{2}$ synthesized via a citric acidassisted sol-gel method, in order to determine the optimal conditions for the synthesis [72]. In particular, the presence of oxygen in the calcination atmosphere effectively increases the percentage of $\mathrm{Ni}^{3+}$ (Fig. 9a-c), leading to a decrease of cation disorder and reduced formation of $\mathrm{LiOH}$ and $\mathrm{Li}_{2} \mathrm{CO}_{3}$ on the surface of $\mathrm{LiNi}_{0.6} \mathrm{Mn}_{0.2} \mathrm{Co}_{0.2} \mathrm{O}_{2}$. Furthermore, heat treatment in an oxygen atmosphere also enhances the uniformity of oxidation state of $\mathrm{Ni}$ ions from the surface to the bulk. The superior structural properties obtained in $\mathrm{O}_{2}$ atmosphere account for the improved rate capability and long-term cycling performance (89\% capacity retention after 100 cycles) of $\mathrm{LiNi}_{0.6} \mathrm{Mn}_{0.2} \mathrm{Co}_{0.2} \mathrm{O}_{2}$ (Fig. 9d-e). Their results further substantiate the importance of minimizing the oxygen non-stoichiometry for the synthesis of Ni-rich layered oxides for high performance LIBs.

Shim et al. compared the calcination atmosphere, i.e., air or oxygen, on the structure and electrochemical performance of a Ni-rich cathode, $\mathrm{LiNi}_{0.80} \mathrm{Mn}_{0.05} \mathrm{Co}_{0.15} \mathrm{O}_{2}$ [68]. The $\mathrm{LiNi}_{0.80} \mathrm{Mn}_{0.05} \mathrm{Co}_{0.15} \mathrm{O}_{2}$ heat treated in the oxygen atmosphere shows better electrochemical performance of initial $\left(194 \mathrm{mAh} \mathrm{g}^{-1}\right)$ and retention capacities $\left(185 \mathrm{mAh} \mathrm{g}^{-1}\right)$ at the $50^{\text {th }}$ cycle than the one heat treated in the air atmosphere (initial capacity $185 \mathrm{mAh} \mathrm{g}^{-1}$ and retention capacity at $50^{\text {th }}$ cycle $172 \mathrm{mAh} \mathrm{g}^{-1}$ ). Considerable rock-salt $\mathrm{NiO}$ phase that developed on the surfaces of the 
materials in the less oxidative environment (air atmosphere) is regarded as the origin of the inferior electrochemical performance of material treated in air.

As discussed above, an oxidative condition is necessary for the synthesis of high performance Ni-rich NMC materials, in order to reduce the oxygen non-stoichiometry and maintain the $\mathrm{Ni}$ oxidation state at +3 . However, $\mathrm{LiNi}_{x} \mathrm{Mn}_{\mathrm{y}} \mathrm{Co}_{z} \mathrm{O}_{2}$ with different cationic composition may require different synthesis conditions. The relative contents of $\mathrm{Ni}$ and $\mathrm{Mn}$ in NMC have a direct effect on the optimal calcination temperature of the materials, which should be taken into consideration in addition to the calcination atmosphere. In addition, the performance of the Ni-rich NMC materials is also closely related to the synthesis method and the morphology/particle size of the material precursors. Some synthesis conditions of $\mathrm{LiNi}_{\mathrm{x}} \mathrm{Mn}_{\mathrm{y}} \mathrm{Co}_{\mathrm{z}} \mathrm{O}_{2}$ with different $\mathrm{Ni}$ content from renowned research groups are summarized in Table 1, while several others can be found in Ref. [73]. The relationship of calcination temperatures as a function of $\mathrm{Ni}$ content in $\mathrm{LiNi}_{x} \mathrm{Mn}_{y} \mathrm{Co}_{z} \mathrm{O}_{2}$ materials is further plotted in Fig. 10, based on the data provided in Table 1. Generally, NMC with higher Mn content requires higher calcination temperature to achieve enhanced crystallinity, while NMC with higher Ni content needs to be calcined at a lower temperature. Oxidative atmosphere (oxygen partial pressure higher than ambient atmosphere) is especially required for the heat treatment of materials with nickel content $x \geq 0.8$. The decrease in Ni content and increase in Mn content may greatly reduce the dependence on the oxidative atmosphere, i.e., $\mathrm{O}_{2}$.

Furthermore, it is worth mentioning the effect of oxygen non-stoichiometry on the low $\mathrm{Ni}$ content $\mathrm{LiNi}_{\mathrm{x}} \mathrm{Mn}_{\mathrm{y}} \mathrm{Co}_{\mathrm{z}} \mathrm{O}_{2}$ materials (with nickel content $\mathrm{x} \leq 0.5$ ), especially those with $\mathrm{Ni} / \mathrm{Mn}$ ratio equal to 1:1, such as $\mathrm{LiNi}_{1 / 2} \mathrm{Mn}_{1 / 2} \mathrm{O}_{2}[74], \mathrm{LiNi}_{1 / 3} \mathrm{Mn}_{1 / 3} \mathrm{Co}_{1 / 3} \mathrm{O}_{2}[27,75]$, and $\mathrm{LiNi}_{0.4} \mathrm{Mn}_{0.4} \mathrm{Co}_{0.2} \mathrm{O}_{2}$ [76]. These materials seem to be much more tolerant of the presence of 
oxygen non-stoichiometry, and have been successfully synthesized in air atmosphere and at high temperatures between $900 \sim 1000^{\circ} \mathrm{C}$. With that being said, pure $\mathrm{O}_{2}$ as calcination atmosphere is still often used to improve the oxygen stoichiometry [76-79] and maximize the electrochemical performance of these materials. Kang et al. [77] reported that $\mathrm{LiNi}_{1 / 3} \mathrm{Mn}_{1 / 3} \mathrm{Co}_{1 / 3} \mathrm{O}_{2}$ nanofibers obtained by calcination in oxygen atmosphere showed higher discharge capacity than that prepared in air atmosphere, due to the reduced cation disorder in the host structure. Tan et al. [76] investigated the effects of synthesis conditions on the cation ordering and the electrochemical performance of $\mathrm{LiNi}_{0.4} \mathrm{Mn}_{0.4} \mathrm{Co}_{0.2} \mathrm{O}_{2}$ using a conventional solid-state method between $800 \sim 950^{\circ} \mathrm{C}$. The sample that was prepared at $950^{\circ} \mathrm{C}$ in oxygen possesses the lowest amount of cation disorder $(3.8 \%)$ and superior cycling performance compared to the sample prepared in air with higher cation disorder (4.2\%).

Overall, maintaining the oxygen stoichiometry is beneficial for achieving good electrochemical performance in Ni-rich and conventional layered-structure NMC materials. However, different synthesis methods and synthetic conditions are adopted in different research groups. Besides the calcination temperature and calcination atmosphere $\left(\mathrm{O}_{2}\right.$, air, etc. $)$, other synthetic conditions, such as co-precipitation $\mathrm{pH}$ value [80], particle size [80], and lithium content $[81,82]$, also play important roles in manipulating the material structural properties and thus influencing the electrochemical performance of reported Ni-rich materials. Therefore, it is more convincing to compare the effect of oxygen stoichiometry reported by the same research group when all the other conditions are the same. As summarized in Table 1 and Fig. 10, Sun et al. consistently reported that high performance Ni-rich materials $\mathrm{LiNi}_{\mathrm{x}} \mathrm{Mn}_{\mathrm{y}} \mathrm{Co}_{\mathrm{z}} \mathrm{O}_{2}$ with $\mathrm{Ni}$ content $\mathrm{x}<0.8$ still could be successfully synthesized in air atmosphere, in spite of the presence of a small quantity of oxygen non-stoichiometry. Additionally, the correlation between calcination 
temperatures and $\mathrm{Ni}$ content in $\mathrm{LiNi}_{\mathrm{x}} \mathrm{Mn}_{\mathrm{y}} \mathrm{Co}_{\mathrm{z}} \mathrm{O}_{2}$ materials provides a useful guide to determine an appropriate calcination temperature for the development of high performance Ni-rich cathodes.

One question remaining to be answered is how the oxygen non-stoichiometry varies as a function of material composition ( $\mathrm{Ni}, \mathrm{Mn}, \mathrm{Co})$ and how it affects the material performance, which requires further investigation. Lastly, a slow cooling rate that could help move the oxygen back into the crystal structure during cooling would also be very helpful to reduce the oxygen nonstoichiometry and cation disorder in the Ni-rich NMC cathodes. The effects of cooling rate on the degree of oxygen non-stoichiometry and electrochemical performance of Ni-rich NMC materials remain to be investigated in detail in the future.

\subsection{Oxygen non-stoichiometry in LMR layered-structure cathodes}

LMR layered cathode materials with a composition of $\mathrm{xLi}_{2} \mathrm{MnO}_{3} \cdot(1-\mathrm{x}) \mathrm{LiMO}_{2}(\mathrm{M}=\mathrm{Mn}, \mathrm{Ni}$, Co, or combinations), have been demonstrated to deliver even higher energy density than the high voltage spinel and Ni-rich NMC cathodes [83-86]. The advantages and challenges of LMR cathodes have been discussed in several well-written reviews published by different research groups $[10,11,22,24,87]$. Whether LMR cathode material is a two-phase structure of a trigonal R-3m phase (Fig. 1e) integrated with a $\mathrm{C} 2 / \mathrm{m} \mathrm{Li}_{2} \mathrm{MnO}_{3}$-like phase (Fig. 1f) [88], or sole homogeneous solid solution with C2/m monoclinic symmetry (Fig. 1f) [89, 90] is highly dependent on the synthesis method and synthetic conditions. The fundamental nature of the local crystal structure of LMR cathode materials is still under debate. At low $\mathrm{C}$ rates, typically $\mathrm{C} / 10$, a discharge capacity exceeding $250 \mathrm{mAh} \mathrm{g}^{-1}$ could be achieved for LMR cathodes after activation of the $\mathrm{Li}_{2} \mathrm{MnO}_{3}$ component in the initial charge process, making it potentially a promising material for high-energy-density cathodes [91, 92]. 
Nevertheless, LMR cathodes usually exhibit poor rate performance because of the low conductivity related to their poorly conducting $\mathrm{Li}_{2} \mathrm{MnO}_{3}$ component [93]. The rate performance of LMR cathodes strongly depends on the kinetic factors, including the lithium ion diffusion coefficient within the material structure and the charge transfer reactions that occur at the electrode/electrolyte interface [94]. As mentioned above, the rate capability and cycle life of $\mathrm{LiNi}_{0.5} \mathrm{Mn}_{1.5} \mathrm{O}_{4}$ can be greatly improved by introducing extra oxygen non-stoichiometry, which can be regulated by heat treatment process [35, 49]. Likewise, oxygen non-stoichiometry also plays an important role in influencing the electrochemical performance of LMR cathode materials containing different amounts of $\mathrm{Li}_{2} \mathrm{MnO}_{3}$. Fast quenching of the LMR materials (in air, water, or liquid nitrogen) from high temperature (typically $900^{\circ} \mathrm{C}$ ) has been frequently used to preserve the oxygen non-stoichiometry in order to achieve better electrochemical performance of LMR materials [95-99].

$\mathrm{Li}_{2} \mathrm{MnO}_{3}$ is one of the important components constituting the LMR cathode materials. Therefore, investigating the effects of oxygen non-stoichiometry on $\mathrm{Li}_{2} \mathrm{MnO}_{3}$ provides a useful guide to understand the influence of oxygen non-stoichiometry on the performance of LMR cathodes [100-102]. Pasero et al. first reported the occurrence of oxygen non-stoichiometry in $\mathrm{Li}_{2} \mathrm{MnO}_{3}$, which is correlated with its electrochemical activity. Reversible oxygen loss/reuptake occurs when heating $\mathrm{Li}_{2} \mathrm{MnO}_{3}$ to $1000^{\circ} \mathrm{C}$ [100]. The result of oxygen non-stoichiometry is a partial reduction of $\mathrm{Mn}^{4+}$ to $\mathrm{Mn}^{3+}$ to maintain charge balance, leading to a considerable enhancement in electronic conductivity associated with the possibility of electron hopping between the mixed valence states of Mn. The oxygen non-stoichiometry, accompanied by the appearance of $\mathrm{Mn}^{3+}$, is considered the major mechanism behind the enhanced electrochemical activity of $\mathrm{Li}_{2} \mathrm{MnO}_{3}$. Xiao et al. further investigated in detail the effects of structural defects of 
$\mathrm{Mn}^{3+}$ oxygen non-stoichiometry on the electrochemical performance of $\mathrm{Li}_{2} \mathrm{MnO}_{3}$ samples [33] . Their results clearly demonstrate that the annealed $\mathrm{Li}_{2} \mathrm{MnO}_{3}(\mathrm{ALMO})$, quenched $\mathrm{Li}_{2} \mathrm{MnO}_{3}$ (QLMO), and quenched $\mathrm{Li}_{2} \mathrm{MnO}_{3}$ milled with Super P (MLMO) all show pure C2/m monoclinic phase with stacking faults. MLMO shows the largest amount of $\mathrm{Mn}^{3+}$, followed by QLMO and then ALMO (Fig. 11a-c). The existence of $\mathrm{Mn}^{3+} /$ oxygen non-stoichiometry was found to promote the activation of $\mathrm{Li}_{2} \mathrm{MnO}_{3}$ phase, as reflected by the higher intensity of the lithium deintercalation peaks during the initial charge process (Fig. 11d). MLMO, with the largest amount of oxygen non-stoichiometry $\left(9.7 \% \mathrm{Mn}^{3+}\right)$, delivers the highest initial discharge capacity (168 mAh $\mathrm{g}^{-1}$ ) among all the samples. However, accelerated activation of $\mathrm{Li}_{2} \mathrm{MnO}_{3}$ results in a faster structural transformation to spinel-like phase, leading to rapid capacity degradation (Fig. 11e).

This group then investigated the effects of oxygen non-stoichiometry on a representative LMR cathode, $\mathrm{Li}\left[\mathrm{Li}_{0.2} \mathrm{Ni}_{0.2} \mathrm{Mn}_{0.6}\right] \mathrm{O}_{2-\delta}$, prepared by different heat treatment processes, i.e., naturally cooled in furnace (annealed), quenched in air (quenched), and quenched sample reheated to $900^{\circ} \mathrm{C}$ and then quenched in air (re-quenched). They found that different heat treatment history does not affect the particle morphology (Fig. 12a). Based on the Ni/Mn XPS spectral fitting results, the oxygen non-stoichiometries are estimated to be $\delta=0.017, \delta=0.039$ and $\delta=0.066$, respectively, for annealed, quenched and re-quenched materials (Fig. 12b, c). Increased oxygen non-stoichiometry in $\mathrm{Li}\left[\mathrm{Li}_{0.2} \mathrm{Ni}_{0.2} \mathrm{Mn}_{0.6}\right] \mathrm{O}_{2-\delta}$ facilitates the activation of the $\mathrm{Li}_{2} \mathrm{MnO}_{3}$ component, significantly improving the reversible capacity and the rate capability of the LMR cathode (Fig. 12d, e). The superior performance of the material with higher oxygen non-stoichiometry is ascribed to the increase of lattice $\mathrm{Mn}^{3+} / \mathrm{Ni}^{2+}$, which provides additional electron hopping pathways, and the expanded crystal layer distance that is beneficial for the lithium ion de/intercalation processes. Consistent with the findings of Xiao el al. [33], the 
extensive activation of the $\mathrm{Li}_{2} \mathrm{MnO}_{3}$ component accelerates the layered-to-spinel phase transformation and leads to a relatively faster capacity degradation. Therefore, the amount of $\mathrm{Mn}^{3+}$ /oxygen non-stoichiometry needs to be well controlled during synthesis of LMR cathodes in order to reach a reasonable trade-off between the rate capability and long-term cycling stability.

In addition, Liu et al. compared the performance of $0.5 \mathrm{Li}_{2} \mathrm{MnO}_{3} \cdot 0.5 \mathrm{LiNi}_{1 / 2} \mathrm{Mn}_{1 / 2} \mathrm{O}_{2}$ cooled with furnace, water, or liquid nitrogen, and found that the material quenched by liquid nitrogen showed the best electrochemical performance [103]. More recently, Zhang et al. investigated the mechanism of the cooling effect on the $\mathrm{LMR}$ cathode $0.3 \mathrm{Li}_{2} \mathrm{MnO}_{3} \cdot 0.7 \mathrm{LiNi}_{1 / 2} \mathrm{Mn}_{1 / 2} \mathrm{O}_{2}$, which demonstrated that the material quenched by liquid nitrogen has fewer defects in structure and larger surface area than the naturally cooled material [104]. Interestingly, Zhang et al. reported that a self-adjusted oxygen-partial-pressure approach could induce the formation of $\mathrm{Mn}^{3+}$ inside the $\mathrm{Li}\left[\mathrm{Li}_{0.14} \mathrm{Mn}_{0.47} \mathrm{Ni}_{0.25} \mathrm{Co}_{0.14}\right] \mathrm{O}_{2}$ crystal by simply varying the lithium sources $\left(\mathrm{Li}_{2} \mathrm{CO}_{3}, \mathrm{LiOH}\right.$, $\mathrm{LiNO}_{3}, \mathrm{CH}_{3} \mathrm{COOLi}$ ) [105]. The amount of $\mathrm{Mn}^{3+}$ ions is closely related to the $p \mathrm{O}_{2}$ and the lower oxygen partial pressure gives rise to more $\mathrm{Mn}^{3+}$ in the final product, which follows the order, in terms of lithium sources as used, $\mathrm{Li}_{2} \mathrm{CO}_{3}, \approx \mathrm{LiOH}>\mathrm{LiNO}_{3}>\mathrm{CH}_{3} \mathrm{COOLi}$. In other words, the lower oxygen partial pressure leads to more $\mathrm{Mn}^{3+}$ ions and enhanced activation of the $\mathrm{Li}_{2} \mathrm{MnO}_{3}$ component. As a result, the rate performance of the LMR materials has been improved.

\subsection{Oxygen extraction during electrochemical activation}

Oxygen loss may occur during the electrochemical charge/discharge process, particularly during charge to high voltages, i.e., $\geq 4.5 \mathrm{~V}$. For $\mathrm{LiNi}_{0.5} \mathrm{Mn}_{1.5} \mathrm{O}_{4}$ and Ni-rich $\mathrm{NMC}$ (e.g., $\left.\mathrm{LiNi}_{0.8} \mathrm{Mn}_{0.1} \mathrm{Co}_{0.1} \mathrm{O}_{2}\right), \mathrm{Ni}^{2+} / \mathrm{Ni}^{3+}$ and then the $\mathrm{Ni}^{2+} / \mathrm{Ni}^{3+}$ redox couples are accessible without oxygen evolution during charge processes, because these two redox couples are pinned at the top of the $\mathrm{O} 2 \mathrm{p}$ band $[106,107]$. However, the origin of oxygen loss in LMR cathode materials is 
quite different from those in conventional layered-structure cathodes and has been investigated extensively $[23,25,108-110]$. There is an irreversible voltage plateau at ca. $4.5 \mathrm{~V}$ beyond the oxidation of $\mathrm{Ni}$ and $\mathrm{Co}$, which has been generally explained as an irreversible loss of oxygen from the lattice in light of in-situ XRD study results [20] and differential electrochemical mass spectrometry $[23,86]$. Armstrong et al. [23] demonstrated the oxygen evolution of the LMR cathode $\mathrm{Li}\left[\mathrm{Li}_{0.2} \mathrm{Ni}_{0.2} \mathrm{Mn}_{0.6}\right] \mathrm{O}_{2}$ during charging to $\geq 4.5 \mathrm{~V}$ (Fig. 13a). Their powder neutron diffraction result illustrates that oxygen loss occurs from the surface and is accompanied by diffusion of TM ions to the vacancies created by removal of Li from TM layers. Later, several groups examined the correlation between the oxygen vacancies and the cation redistribution/migration during initial charge and subsequent cycling processes [110-113], which is important for understanding the phase transformation and the consequent capacity/voltage fade occurring in LMR cathodes.

Recently, Qian et al. proposed a novel oxygen-assisted TM ion diffusion mechanism to explain the surface phase transformation in the LMR cathode $\mathrm{Li}\left[\mathrm{Li}_{1 / 6} \mathrm{Ni}_{1 / 4} \mathrm{Mn}_{7 / 12}\right] \mathrm{O}_{2}$ [112]. Their electron energy loss spectroscopy (EELS) characterization data demonstrate that the oxygen vacancies mainly formed in the surface region where the spinel-like phase is identified, and diminished toward the inner bulk of the layered structure, as evidenced by increased intensity of the $\mathrm{O} K$ pre-edge peak (Fig. 13b). Based on the computational calculations, oxygen anions in the local environments composed of Li-Ni-Mn combinations in the TM layer show the lowest oxygen vacancy formation energy $\left(\mathrm{E}_{\text {fov }}\right)$ as compared to other configurations (Fig. 13c), indicating a higher possibility for the formation of oxygen vacancies in this case. The consequence of the oxygen vacancies is a significant decrease of the energy barrier for TM ion migration into the Li layer [110], which causes the spinel-like phase formation and limits the 
rate/cycling performances of LMR cathodes. From this point of view, oxygen vacancies created in the electrochemical charge process should be stabilized through effective lattice doping and surface coating [114], to mitigate the phase transformation and thus improve the capacity/voltage stability during long-term cycling.

\subsection{Oxygen-release-related thermal stability}

Safety has become one of the primary concerns for the widespread application of highcapacity, high-energy-density LIBs in the automobile industry. Poor thermal stability of the charged cathode materials is one of the primary concerns during thermal runaway, which triggers oxygen loss from the charged cathode materials. The oxygen species released from the delithiated cathode are highly reactive with the electrolyte. The aggressive thermal reactions between oxygen species and the electrolyte generate lots of heat and gas in a short time, leading to sudden inner temperature rise, build-up of cell pressure, and eventual explosion of the batteries. Here, we give a brief overview on the thermal stability of the three high-energy-density cathode materials from the oxygen loss point of view.

$\mathrm{Hu}$ et al. discovered the oxygen-release-related thermal stability and decomposition pathways for the high voltage spinel $\mathrm{Li}_{\mathrm{x}} \mathrm{Ni}_{0.5} \mathrm{Mn}_{1.5} \mathrm{O}_{4}$ with ordered and disordered structures in the fully delithiated state [115]. When fully charged, both ordered and disordered $\mathrm{Li}_{\mathrm{X}} \mathrm{Ni}_{0.5} \mathrm{Mn}_{1.5} \mathrm{O}_{4} \mathrm{spinels}$ demonstrate oxygen release and structural changes at temperatures below $300^{\circ} \mathrm{C}$. These are mainly ascribed to the presence of $\mathrm{Ni}^{4+}$ in $\mathrm{Li}_{\mathrm{x}} \mathrm{Ni}_{0.5} \mathrm{Mn}_{1.5} \mathrm{O}_{4}$, which experiences dramatic reduction related to oxygen release. Because of the $\mathrm{Ni} / \mathrm{Mn}$ cation ordering and limited amount of the rocksalt impurity phase in ordered spinel phase, charged ordered spinel shows superior thermal stability with oxygen release initiated at $\sim 250^{\circ} \mathrm{C}$ as compared to the disordered counterpart, which shows oxygen release at a much lower temperature of $\sim 210^{\circ} \mathrm{C}$ (Fig. 14a). They also found 
that two thermal-decomposition pathways from the initial $\mathrm{Li}_{\mathrm{x}} \mathrm{Ni}_{0.5} \mathrm{Mn}_{1.5} \mathrm{O}_{4}$ spinel to the final $\mathrm{NiMn}_{2} \mathrm{O}_{4}$-type spinel structure, with and without the intermediate phases $\left(\mathrm{NiMnO}_{3}\right.$ and $\alpha$ $\mathrm{Mn}_{2} \mathrm{O}_{3}$ ), play critical roles in the thermal stability and oxygen release of $\mathrm{Li}_{\mathrm{x}} \mathrm{Ni}_{0.5} \mathrm{Mn}_{1.5} \mathrm{O}_{4}$ during thermal decomposition.

Noh et al. reported the effects of the Ni content on the electrochemical performance and the thermal stability of $\mathrm{Li}\left[\mathrm{Ni}_{\mathrm{x}} \mathrm{Mn}_{\mathrm{y}} \mathrm{Co}_{\mathrm{z}}\right] \mathrm{O}_{2}$ with $\mathrm{x}$ ranging from $1 / 3$ to 0.85 [116]. The electrochemical properties and thermal stability of $\mathrm{Li}\left[\mathrm{Ni}_{\mathrm{x}} \mathrm{Mn}_{\mathrm{y}} \mathrm{Co}_{\mathrm{z}}\right] \mathrm{O}_{2}$ are directly related to its cationic composition (Fig. 14b). Higher Ni content gives rise to an increase of discharge capacity, which, however, gradually compromises the corresponding cycle life and safety characteristics. The onset temperature for oxygen release and the content of released oxygen dramatically increase with increasing Ni content in the materials. Similar to the easy formation of oxygen nonstoichiometry in Ni-rich NMCs at calcination temperatures, the oxygen release during thermal reactions incidentally induces the reduction of $\mathrm{Ni}$ from $\mathrm{Ni}^{4+}$ to $\mathrm{Ni}^{2+}$, accompanied by formation of Ni-O type rock-salt phase [117]. Thus it is suggested that the composition of $\mathrm{Li}\left[\mathrm{Ni}_{\mathrm{x}} \mathrm{Mn}_{\mathrm{y}} \mathrm{Co}_{\mathrm{z}}\right] \mathrm{O}_{2}$ be specifically designed according to the required applications, to achieve a good trade-off between capacity and safety.

The LMR cathode materials reportedly show good thermal stability, with onset of thermal decomposition at $250^{\circ} \mathrm{C}[118,119]$, which is better than the traditional $\mathrm{LiCoO}_{2}$ [119]. Geder et al. investigated the thermal stability of an LMR cathode material with composition $\mathrm{Li}_{1.167} \mathrm{Mn}_{0.5} \mathrm{Ni}_{0.167} \mathrm{Co}_{0.167} \mathrm{O}_{2}$ by $\mathrm{TG}$ analysis and differential scanning calorimetry [119]. During the initial charge, decomposition onset temperature remains around $276 \sim 296^{\circ} \mathrm{C}$ until $250 \mathrm{mAh} \mathrm{g}^{-}$ ${ }^{1}$, but decreases to $238^{\circ} \mathrm{C}$ at $300 \mathrm{mAh} \mathrm{g}^{-1}$ (Fig. 14c). The decrease in onset temperature during the later part of charging is ascribed to the formation of unstable oxidized oxygen species in the 
delithiated material. Activation of $\mathrm{Li}_{2} \mathrm{MnO}_{3}$ is found to show an ambivalent effect on the thermal stability of LMR cathodes: the onset temperature of cathode decomposition is increased in the second charge, which is attributed to the changes in oxidation states of TM ions after the initial activation; the enthalpy of thermal decomposition increases, owing to the formation of unstable oxygen in the lattice. The variable oxygen non-stoichiometry in the delithiated cathode also leads to different thermal-decomposition reaction paths and the formation of different decomposition products.

Based on the discussion above, suppressing or delaying the oxygen loss is the key to enhancing the safety of LIBs. Surface coating / lattice doping that could effectively stabilize the cathode structural stability and use of electrolyte /additives with improved oxidation stability are the facile strategies for enhancing the thermal stability of high voltage spinel [12, 120], Ni-rich NMC cathode materials [121, 122], and LMR cathodes [86, 123].

\section{Conclusions and perspectives}

In summary, oxygen non-stoichiometry plays an important role in governing the structural properties, electrochemical performance, and thermal stability of the high-energy-density cathode materials: high voltage spinel, Ni-rich NMCs, and LMR cathode materials. The oxygen non-stoichiometry adversely or beneficially affects the electrochemical performance of the cathode materials, depending on the material's crystal structure and cationic composition. The conclusions and perspectives in relation to the oxygen non-stoichiometry in these three highenergy-density cathode materials are summarized as follows:

(1) High voltage spinel $\mathrm{LiNi}_{0.5} \mathrm{Mn}_{1.5} \mathrm{O}_{4}$ : Oxygen non-stoichiometry is beneficial for tuning the local crystal structure and manipulating the phase transition between ordered and disordered phase. Lattice $\mathrm{Mn}^{3+}$ incidentally induced by oxygen non-stoichiometry significantly enhances the 
electrical conduction of the disordered spinel, leading to superior electrochemical performance as compared to ordered spinel without oxygen non-stoichiometry. However, disordered $\mathrm{LiNi}_{0.5} \mathrm{Mn}_{1.5} \mathrm{O}_{4}$ in the fully charged state shows inferior thermal stability, with lower onset temperature for oxygen release as compared to ordered phase. Moreover, despite the positive effects brought by oxygen non-stoichiometry and lattice $\mathrm{Mn}^{3+}$, the potentially damaging JahnTeller distortion effects of $\mathrm{Mn}^{3+}$ should be carefully considered in a full-cell configuration using graphite as anode. Tuning the post-annealing time is an effective approach to keep oxygen nonstoichiometry at a reasonable level and reach a good balance between ordered and disordered phases, and produce a material with both high performance and improved safety.

(2) Ni-rich NMC materials, e.g., $\mathrm{LiNi}_{0.8} \mathrm{Mn}_{0.1} \mathrm{Co}_{0.1} \mathrm{O}_{2}$ and $\mathrm{LiNi}_{0.6} \mathrm{Mn}_{0.2} \mathrm{Co}_{0.2} \mathrm{O}_{2}$ : The presence of oxygen non-stoichiometry is detrimental to the electrochemical performance of Ni-rich NMC materials, because it causes the reduction of $\mathrm{Ni}$ from $\mathrm{Ni}^{3+}$ to $\mathrm{Ni}^{2+}$ and results in increased cation disorder, blocking the lithium ion diffusion. Though high performance Ni-rich materials $\mathrm{LiNi}_{\mathrm{x}} \mathrm{Mn}_{\mathrm{y}} \mathrm{Co}_{\mathrm{z}} \mathrm{O}_{2}$ with Ni content $\mathrm{x}<0.8$ could be successfully synthesized in air atmosphere, future investigation is still required to further determine the oxygen non-stoichiometry and its correlation with the electrochemical performance, by comparing to those synthesized in oxygen atmosphere. An optimal calcination temperature should be carefully determined based on the best electrochemical performance that could be achieved, i.e., superior rate capability and cycling stability. This is not only to minimize the degree of oxygen non-stoichiometry, but also to optimize the primary particle size in order to avoid the harmful effects that result from the build-up of internal stress and crack formation. Safety should be always the primary consideration, because the increase of $\mathrm{Ni}$ content leads to an almost linear decrease in the thermal stability of the $\mathrm{LiNi}_{\mathrm{x}} \mathrm{Mn}_{\mathrm{y}} \mathrm{Co}_{\mathrm{z}} \mathrm{O}_{2}$ electrodes. Designing the material synthesis with core- 
shell and concentration-gradient structure, with core rich in $\mathrm{Ni}$ and shell rich in $\mathrm{Mn}$ or $\mathrm{Al}$, and/or additional inert cation/anion doping and surface modification could improve the thermal stability of Ni-rich NMC materials.

(3) LMR cathodes, e.g., $\mathrm{Li}\left[\mathrm{Li}_{0.2} \mathrm{Mn}_{0.54} \mathrm{Ni}_{0.13} \mathrm{Co}_{0.13}\right] \mathrm{O}_{2}$ : Energy densities of LMR cathodes $\left(\sim 900 \mathrm{Wh} \mathrm{kg}^{-1}\right)$ are among the highest of all known cathode materials. However, several technical hurdles, including voltage fade, relatively low initial Coulombic efficiency, long-term cycling instability, and poor rate capability, still impede the practical application of these LMR cathode materials. Similar to $\mathrm{LiNi}_{0.5} \mathrm{Mn}_{1.5} \mathrm{O}_{4}$, oxygen non-stoichiometry and the induced $\mathrm{Mn}^{3+}$ are beneficial for enhancing the electrical conduction of LMR cathodes, which promotes the activation of the $\mathrm{Li}_{2} \mathrm{MnO}_{3}$ component and greatly improves their rate capability. Oxygen loss and oxygen non-stoichiometry also exist in the electrodes with electrochemical activation process and thermal runaway reactions of charged electrodes. The oxygen non-stoichiometry formed at the material particle surface during the charge process is the main reason for the surface phase transformation from layered to spinel-like/disordered rock-salt phase, resulting in capacity/voltage fade as a consequence. Overall, the LMR cathode materials exhibit relatively good thermal stability even when charged to a high cut-off voltage of 4.6-4.8 V. The LMR cathodes that are under investigation are mostly nano-sized; these suffer from low packing density $\left(1.6 \sim 1.8 \mathrm{~g} \mathrm{~cm}^{-3}\right.$ ) and thus low volumetric energy density in $\mathrm{Wh} \mathrm{L}^{-1}$. In addition to extra surface coating/lattice doping, controlling the oxygen non-stoichiometry to a reasonable level would be helpful for the future development of high-tap-density and high performance LMR cathode materials. 


\section{Acknowledgements}

This work is supported by the Assistant Secretary for Energy Efficiency and Renewable Energy, Office of Vehicle Technologies of the U. S. Department of Energy under Contract No. DE-AC02-05CH11231, Subcontract No. 18769, under the Advanced Battery Materials Research program. The authors would like to thank Mr. Mark H. Engelhard for XPS measurements as shown in Fig. 12, which were conducted in William R. Wiley Environmental Molecular Sciences Laboratory, a national scientific user facility sponsored by the U.S. Department of Energy's Office of Biological and Environmental Research and located at Pacific Northwest National Laboratory.

\section{References}

[1] J.M. Tarascon, M. Armand, Nature, 414 (2001) 359-367.

[2] M. Armand, J.M. Tarascon, Nature, 451 (2008) 652-657.

[3] C. Chae, H.-J. Noh, J.K. Lee, B. Scrosati, Y.-K. Sun, Adv. Funct. Mater., 24 (2014) 3036-3042.

[4] J. Zheng, P. Yan, R. Cao, H. Xiang, M.H. Engelhard, B.J. Polzin, C. Wang, J.-G. Zhang, W. Xu, ACS Appl. Mater. Interfaces, 8 (2016) 5715-5722.

[5] Q. Huang, T. Wang, M. Yan, Z. Jiang, J. Electrochem. Soc., 153 (2006) A2363-A2369.

[6] M.S. Whittingham, Proc. IEE, 100 (2012) 1518-1534.

[7] J.-H. Shim, K.-S. Lee, A. Missyul, J. Lee, B. Linn, E.C. Lee, S. Lee, Chem. Mater., 27 (2015) 3273-3279.

[8] A. Manthiram, K. Chemelewski, E.-S. Lee, Energy Environ. Sci., 7 (2014) 1339-1350.

[9] W. Liu, P. Oh, X. Liu, M.-J. Lee, W. Cho, S. Chae, Y. Kim, J. Cho, Angew. Chem. Int. Ed., 54 (2015) 4440-4457.

[10] S. Hy, H. Liu, D. Qian, M. Zhang, B.J. Hwang, Y.S. Meng, Energy Environ. Sci., (2016). 
[11] A. Manthiram, J.C. Knight, S.-T. Myung, S.-M. Oh, Y.-K. Sun, Adv. Energy Mater., 6 (2016) 10.1002/aenm.201501010.

[12] J.-H. Cho, J.-H. Park, M.-H. Lee, H.-K. Song, S.-Y. Lee, Energy Environ. Sci., 5 (2012) 7124-7131.

[13] Z. Zhang, L. Hu, H. Wu, W. Weng, M. Koh, P.C. Redfern, L.A. Curtiss, K. Amine, Energy Environ. Sci., 6 (2013) 1806-1810.

[14] M. Xu, L. Zhou, Y. Dong, Y. Chen, J. Demeaux, A.D. MacIntosh, A. Garsuch, B.L. Lucht, Energy Environ. Sci., 9 (2016) 1308-1319.

[15] M. Kunduraci, J.F. Al-Sharab, G.G. Amatucci, Chem. Mater., 18 (2006) 3585-3592.

[16] J. Hassoun, S. Panero, P. Reale, B. Scrosati, Adv. Mater., 21 (2009) 4807-4810.

[17] W. Xu, X. Chen, F. Ding, J. Xiao, D. Wang, A. Pan, J. Zheng, X.S. Li, A.B. Padmaperuma, J.-G. Zhang, J. Power Sources, 213 (2012) 304-316.

[18] Y.-K. Sun, Z. Chen, H.-J. Noh, D.-J. Lee, H.-G. Jung, Y. Ren, S. Wang, C.S. Yoon, S.-T. Myung, K. Amine, Nat Mater, 11 (2012) 942-947.

[19] Y.-K. Sun, S.-T. Myung, B.-C. Park, J. Prakash, I. Belharouak, K. Amine, Nat Mater, 8 (2009) 320-324.

[20] Z. Lu, J.R. Dahn, J. Electrochem. Soc., 149 (2002) A815-A822.

[21] S.H. Kang, K. Amine, J. Power Sources, 146 (2005) 654-657.

[22] M.M. Thackeray, C.S. Johnson, J.T. Vaughey, N. Li, S.A. Hackney, J. Mater. Chem., 15 (2005) 2257-2267.

[23] A.R. Armstrong, M. Holzapfel, P. Novák, C.S. Johnson, S.-H. Kang, M.M. Thackeray, P.G. Bruce, J. Am. Chem. Soc., 128 (2006) 8694-8698.

[24] M.M. Thackeray, S.-H. Kang, C.S. Johnson, J.T. Vaughey, R. Benedek, S.A. Hackney, J. Mater. Chem., 17 (2007) 3112-3125.

[25] N. Yabuuchi, K. Yoshii, S.-T. Myung, I. Nakai, S. Komaba, J. Am. Chem. Soc., 133 (2011) 4404-4419.

[26] Y.-K. Sun, M.-J. Lee, C.S. Yoon, J. Hassoun, K. Amine, B. Scrosati, Adv. Mater., 24 (2012) 1192-1196.

[27] M.H. Lee, Y.J. Kang, S.T. Myung, Y.K. Sun, Electrochim. Acta, 50 (2004) 939-948.

[28] H. Liu, J. Li, Z. Zhang, Z. Gong, Y. Yang, J. Solid State Electrochem., 7 (2003) 456-462.

[29] A. van Bommel, J.R. Dahn, Chem. Mater., 21 (2009) 1500-1503. 
[30] D. Pasero, N. Reeves, L.J. Gillie, A.R. West, J. Power Sources, 174 (2007) 1078-1081.

[31] M.S. Idris, A.R. West, J. Electrochem. Soc., 159 (2012) A396-A401.

[32] J. Xiao, X. Chen, P.V. Sushko, M.L. Sushko, L. Kovarik, J. Feng, Z. Deng, J. Zheng, G.L. Graff, Z. Nie, D. Choi, J. Liu, J.-G. Zhang, M.S. Whittingham, Adv. Mater., 24 (2012) 2109-2116.

[33] L. Xiao, J. Xiao, X. Yu, P. Yan, J. Zheng, M. Engelhard, P. Bhattacharya, C. Wang, X.Q. Yang, J.-G. Zhang, Nano Energy, 16 (2015) 143-151.

[34] M. Kuhn, J.J. Kim, S.R. Bishop, H.L. Tuller, Chem. Mater., 25 (2013) 2970-2975.

[35] J. Zheng, J. Xiao, X. Yu, L. Kovarik, M. Gu, F. Omenya, X. Chen, X.-Q. Yang, J. Liu, G.L. Graff, M.S. Whittingham, J.-G. Zhang, Phys. Chem. Chem. Phys., 14 (2012) $13515-13521$.

[36] D.N. Mueller, R.A. De Souza, H.-I. Yoo, M. Martin, Chem. Mater., 24 (2012) 269-274.

[37] F. Wang, T. Nakamura, K. Yashiro, J. Mizusaki, K. Amezawa, Phys. Chem. Chem. Phys., 16 (2014) 7307-7314.

[38] J. Sugiyama, T. Atsumi, T. Hioki, S. Noda, N. Kamegashira, J Alloy. Compd., 235 (1996) 163-169.

[39] C. Masquelier, M. Tabuchi, K. Ado, R. Kanno, Y. Kobayashi, Y. Maki, O. Nakamura, J.B. Goodenough, J. Solid State Chem., 123 (1996) 255-266.

[40] R. Kanno, M. Yonemura, T. Kohigashi, Y. Kawamoto, M. Tabuchi, T. Kamiyama, J. Power Sources, 97-98 (2001) 423-426.

[41] A.R. Naghash, J.Y. Lee, J. Power Sources, 102 (2001) 68-73.

[42] J. Sugiyama, T. Atsumi, T. Hioki, S. Noda, N. Kamegashira, J. Power Sources, 68 (1997) 641-645.

[43] J.H. Kim, S.T. Myung, C.S. Yoon, S.G. Kang, Y.K. Sun, Chem. Mater., 16 (2004) 906914.

[44] E. Lee, K.A. Persson, Energy Environ. Sci., 5 (2012) 6047-6051.

[45] Y. Chen, Y. Sun, X. Huang, Comp. Mater. Sci., 115 (2016) 109-116.

[46] M. Kunduraci, G.G. Amatucci, J. Electrochem. Soc., 153 (2006) A1345-A1352.

[47] L. Wang, H. Li, M. Courty, X. Huang, E. Baudrin, J. Power Sources, 232 (2013) 165172.

[48] H. Xia, Y.S. Meng, L. Lu, G. Ceder, J. Electrochem. Soc., 154 (2007) A737-A743. 
[49] Y.-C. Jin, C.-Y. Lin, J.-G. Duh, Electrochim. Acta, 69 (2012) 45-50.

[50] H. Liu, J. Wang, X. Zhang, D. Zhou, X. Qi, B. Qiu, J. Fang, R. Kloepsch, G. Schumacher, Z. Liu, J. Li, ACS Appl. Mater. Interfaces, 8 (2016) 4661-4675.

[51] D. Pasero, N. Reeves, V. Pralong, A.R. West, J. Electrochem. Soc., 155 (2008) A282A291.

[52] S. Patoux, L. Sannier, H. Lignier, Y. Reynier, C. Bourbon, S. Jouanneau, F. Le Cras, S. Martinet, Electrochim. Acta, 53 (2008) 4137-4145.

[53] L. Wang, H. Li, X. Huang, E. Baudrin, Solid State Ionics, 193 (2011) 32-38.

[54] J. Song, D.W. Shin, Y. Lu, C.D. Amos, A. Manthiram, J.B. Goodenough, Chem. Mater., 24 (2012) 3101-3109.

[55] X. Ma, B. Kang, G. Ceder, J. Electrochem. Soc., 157 (2010) A925-A931.

[56] J. Zheng, J. Xiao, Z. Nie, J.-G. Zhang, J. Electrochem. Soc., 160 (2013) A1264-A1268.

[57] D. Li, A. Ito, K. Kobayakawa, H. Noguchi, Y. Sato, Electrochim. Acta, 52 (2007) 19191924.

[58] J. Wang, W. Lin, B. Wu, J. Zhao, J. Mater. Chem. A, 2 (2014) 16434-16442.

[59] K.R. Chemelewski, E.-S. Lee, W. Li, A. Manthiram, Chem. Mater., 25 (2013) 28902897.

[60] X. Zhang, F. Cheng, J. Yang, J. Chen, Nano Lett., 13 (2013) 2822-2825.

[61] J.-H. Kim, A. Huq, M. Chi, N.P.W. Pieczonka, E. Lee, C.A. Bridges, M.M. Tessema, A. Manthiram, K.A. Persson, B.R. Powell, Chem. Mater., 26 (2014) 4377-4386.

[62] A. Manthiram, A. Vadivel Murugan, A. Sarkar, T. Muraliganth, Energy Environ. Sci., 1 (2008) 621-638.

[63] J.B. Goodenough, K.-S. Park, J. Am. Chem. Soc., 135 (2013) 1167-1176.

[64] K.-S. Lee, S.-T. Myung, K. Amine, H. Yashiro, Y.-K. Sun, J. Electrochem. Soc., 154 (2007) A971-A977.

[65] Y. Koyama, H. Arai, I. Tanaka, Y. Uchimoto, Z. Ogumi, J. Power Sources, 244 (2013) 592-596.

[66] Y. Koyama, H. Arai, I. Tanaka, Y. Uchimoto, Z. Ogumi, Chem. Mater., 24 (2012) 38863894.

[67] X.-q. Li, X.-h. Xiong, Z.-x. Wang, Q.-y. Chen, Trans. Nonferrous Met. Soc. China, 24 (2014) 4023-4029. 
[68] J.-H. Shim, C.-Y. Kim, S.-W. Cho, A. Missiul, J.-K. Kim, Y.J. Ahn, S. Lee, Electrochim. Acta, 138 (2014) 15-21.

[69] Y. Bi, W. Yang, R. Du, J. Zhou, M. Liu, Y. Liu, D. Wang, J. Power Sources, 283 (2015) 211-218.

[70] D. Wang, Vehicle Technologies Office Annual Merit Review, (2015) es212_wang_2015_p.

[71] J. Zheng, W.H. Kan, A. Manthiram, ACS Appl. Mater. Interfaces, 7 (2015) 6926-6934.

[72] S.-W. Lee, H. Kim, M.-S. Kim, H.-C. Youn, K. Kang, B.-W. Cho, K.C. Roh, K.-B. Kim, J. Power Sources, 315 (2016) 261-268.

[73] L. Wang, J. Li, X. He, W. Pu, C. Wan, C. Jiang, J. Solid State Electrochem., 13 (2008) $1157-1164$.

[74] H. Lin, J. Zheng, Y. Yang, Mater. Chem. Phys., 119 (2010) 519-523.

[75] J. Li, Z.R. Zhang, X.J. Guo, Y. Yang, Solid State Ionics, 177 (2006) 1509-1516.

[76] T.Q. Tan, M.S. Idris, R.A.M. Osman, M.V. Reddy, B.V.R. Chowdari, Solid State Ionics, 278 (2015) 43-48.

[77] C.-S. Kang, J.-T. Son, J. Electroceram., 29 (2012) 235-239.

[78] Q. Jiang, K. Du, Y. He, Electrochim. Acta, 107 (2013) 133-138.

[79] V.S.R. Channu, D. Ravichandran, B. Rambabu, R. Holze, Colloids Surf A Physicochem Eng Asp., 453 (2014) 125-131.

[80] I. Hwang, C.W. Lee, J.C. Kim, S. Yoon, Mater. Res. Bull., 47 (2012) 73-78.

[81] C. Fu, G. Li, D. Luo, Q. Li, J. Fan, L. Li, ACS Appl. Mater. Interfaces, 6 (2014) 1582215831.

[82] F. Wu, J. Tian, Y. Su, J. Wang, C. Zhang, L. Bao, T. He, J. Li, S. Chen, ACS Appl. Mater. Interfaces, 7 (2015) 7702-7708.

[83] M.M. Thackeray, C.S. Johnson, J.T. Vaughey, N. Li, S.A. Hackney, J. Mater. Chem., 15 (2005) 2257.

[84] M.M. Thackeray, S.-H. Kang, C.S. Johnson, J.T. Vaughey, R. Benedek, S.A. Hackney, J. Mater. Chem., 17 (2007) 3112.

[85] J. Zheng, X. Wu, Y. Yang, Electrochim. Acta, 105 (2013) 200-208.

[86] J.M. Zheng, Z.R. Zhang, X.B. Wu, Z.X. Dong, Z. Zhu, Y. Yang, J. Electrochem. Soc., 155 (2008) A775-A782. 
[87] H. Yu, H. Zhou, J. Phys. Chem. Lett., 4 (2013) 1268-1280.

[88] H. Yu, R. Ishikawa, Y.-G. So, N. Shibata, T. Kudo, H. Zhou, Y. Ikuhara, Angew. Chem. Int. Ed., 52 (2013) 5969-5973.

[89] K.A. Jarvis, Z.-Q. Deng, L.F. Allard, A. Manthiram, P.J. Ferreira, Chem. Mater., 23 (2011) 3614-3621.

[90] J. Zheng, M. Gu, A. Genc, J. Xiao, P. Xu, X. Chen, Z. Zhu, W. Zhao, L. Pullan, C. Wang, J.-G. Zhang, Nano Lett., 14 (2014) 2628-2635.

[91] J. Zheng, M. Gu, J. Xiao, P. Zuo, C. Wang, J.-G. Zhang, Nano Lett., 13 (2013) 38243830.

[92] M. Gu, I. Belharouak, J. Zheng, H. Wu, J. Xiao, A. Genc, K. Amine, S. Thevuthasan, D.R. Baer, J.-G. Zhang, N.D. Browning, J. Liu, C. Wang, ACS Nano, 7 (2013) 760-767.

[93] C. Yu, H. Wang, X. Guan, J. Zheng, L. Li, J. Alloys Compd., 546 (2013) 239-245.

[94] J. Zheng, W. Shi, M. Gu, J. Xiao, P. Zuo, C. Wang, J.-G. Zhang, J. Electrochem. Soc., 160 (2013) A2212-A2219.

[95] X.-J. Guo, Y.-X. Li, M. Zheng, J.-M. Zheng, J. Li, Z.-L. Gong, Y. Yang, J. Power Sources, 184 (2008) 414-419.

[96] Q.Y. Wang, J. Liu, A.V. Murugan, A. Manthiram, J. Mater. Chem., 19 (2009) 49654972.

[97] J. Gao, A. Manthiram, J. Power Sources, 191 (2009) 644-647.

[98] G. Singh, R. Thomas, A. Kumar, R.S. Katiyar, J. Electrochem. Soc., 159 (2012) A410A420.

[99] X. Bian, Q. Fu, X. Bie, P. Yang, H. Qiu, Q. Pang, G. Chen, F. Du, Y. Wei, Electrochim. Acta, 174 (2015) 875-884.

[100] D. Pasero, V. McLaren, S. de Souza, A.R. West, Chem. Mater., 17 (2005) 345-348.

[101] K. Kubota, T. Kaneko, M. Hirayama, M. Yonemura, Y. Imanari, K. Nakane, R. Kanno, J. Power Sources, 216 (2012) 249-255.

[102] Y. Okamoto, J. Electrochem. Soc., 159 (2012) A152-A157.

[103] Y. Liu, S. Liu, Ionics, 19 (2012) 477-481.

[104] Y. Zhang, Y. Zhang, L. Wang, X. He, J. Yang, Y. Jin, K. Zhang, Ionics, 21 (2015) 18191825. 
[105] X. Zhang, D. Luo, G. Li, J. Zheng, C. Yu, X. Guan, C. Fu, X. Huang, L. Li, J. Mater. Chem. A, 1 (2013) 9721-9729.

[106] J.B. Goodenough, Y. Kim, Chem. Mater., 22 (2010) 587-603.

[107] C. Julien, A. Mauger, K. Zaghib, H. Groult, Inorganics, 2 (2014) 132-154.

[108] W.-S. Yoon, N. Kim, X.-Q. Yang, J. McBreen, C.P. Grey, J. Power Sources, 119-121 (2003) 649-653.

[109] N. Tran, L. Croguennec, M. Ménétrier, F. Weill, P. Biensan, C. Jordy, C. Delmas, Chem. Mater., 20 (2008) 4815-4825.

[110] B. Xu, C.R. Fell, M. Chi, Y.S. Meng, Energy Environ. Sci., 4 (2011) 2223-2233.

[111] C.R. Fell, D. Qian, K.J. Carroll, M. Chi, J.L. Jones, Y.S. Meng, Chem. Mater., 25 (2013) 1621-1629.

[112] D. Qian, B. Xu, M. Chi, Y.S. Meng, Phys. Chem. Chem. Phys., 16 (2014) 14665-14668.

[113] A. Boulineau, L. Simonin, J.-F. Colin, C. Bourbon, S. Patoux, Nano Lett., 13 (2013) 3857-3863.

[114] Y. Wu, A. Manthiram, Solid State Ionics, 180 (2009) 50-56.

[115] E. Hu, S.-M. Bak, J. Liu, X. Yu, Y. Zhou, S.N. Ehrlich, X.-Q. Yang, K.-W. Nam, Chem. Mater., 26 (2014) 1108-1118.

[116] H.-J. Noh, S. Youn, C.S. Yoon, Y.-K. Sun, J. Power Sources, 233 (2013) 121-130.

[117] L. Wu, K.-W. Nam, X. Wang, Y. Zhou, J.-C. Zheng, X.-Q. Yang, Y. Zhu, Chem. Mater., 23 (2011) 3953-3960.

[118] H. Deng, I. Belharouak, Y.-K. Sun, K. Amine, J. Mater. Chem., 19 (2009) 4510-4516.

[119] J. Geder, J.H. Song, S.H. Kang, D.Y.W. Yu, Solid State Ionics, 268, Part B (2014) 242246.

[120] Q. Zhang, J.-J. Chen, X.-Y. Wang, C. Yang, M.-S. Zheng, Q.-F. Dong, Phys. Chem. Chem. Phys., 17 (2015) 10353-10357.

[121] S.-U. Woo, B.-C. Park, C.S. Yoon, S.-T. Myung, J. Prakash, Y.-K. Sun, J. Electrochem. Soc., 154 (2007) A649-A655.

[122] W. Cho, S.-M. Kim, K.-W. Lee, J.H. Song, Y.N. Jo, T. Yim, H. Kim, J.-S. Kim, Y.-J. Kim, Electrochim. Acta, 198 (2016) 77-83.

[123] J. Zheng, D. Zhu, Y. Yang, Y. Fung, Electrochim. Acta, 59 (2012) 14-22. 
[124] C.S. Yoon, M.H. Choi, B.-B. Lim, E.-J. Lee, Y.-K. Sun, J. Electrochem. Soc., 162 (2015) A2483-A2489.

[125] H. Kim, S. Lee, H. Cho, J. Kim, J. Lee, S. Park, S.H. Joo, S.H. Kim, Y.-G. Cho, H.-K. Song, S.K. Kwak, J. Cho, Adv. Mater., (2016) 10.1002/adma.201506256.

[126] S.-J. Yoon, K.-J. Park, B.-B. Lim, C.S. Yoon, Y.-K. Sun, J. Electrochem. Soc., 162 (2015) A3059-A3063.

[127] Y.-K. Sun, D.-H. Kim, C.S. Yoon, S.-T. Myung, J. Prakash, K. Amine, Adv. Funct. Mater., 20 (2010) 485-491.

[128] Y. Cho, P. Oh, J. Cho, Nano Lett., 13 (2013) 1145-1152.

[129] Y.-K. Sun, H.-B. Kang, S.-T. Myung, J. Prakash, J. Electrochem. Soc., 157 (2010) A1335-A1340.

[130] H.-G. Kim, S.-T. Myung, J.K. Lee, Y.-K. Sun, J. Power Sources, 196 (2011) 6710-6715. 


\section{Table Caption}

Table 1 Synthesis conditions of $\mathrm{LiNi}_{\mathrm{x}} \mathrm{Mn}_{\mathrm{y}} \mathrm{Co}_{\mathrm{z}} \mathrm{O}_{2}$ with different $\mathrm{Ni}$ content

\section{Figure Captions}

Figure 1 (a) Typical discharge voltage profiles of different cathode materials. (b) Energy density profiles of different cathode materials. (c-f) Atomic models showing the (c) ordered spinel structure with space group $\mathrm{P}_{3} 32$, (d) disordered spinel structure with space group Fd-3m,

(e) layered structure with space group R-3m, and (f) monoclinic structure with space group $\mathrm{C} 2 / \mathrm{m}$. The fire represents the high temperature calcination process that leads to the formation of non-stoichiometry in the as-prepared materials. $\mathrm{TM}=$ transition metal.

Figure 2 (a) The shapes of $\mathrm{Mn}(\mathrm{Ni}) \mathrm{O}_{6}$ octahedra in $\mathrm{P}_{4} 32$ and Ni-dimer supercells. (b) Local atomic structures of the most energetically favorable oxygen vacancy in Ni aggregated supercells. (c) Formation energies of one or two oxygen vacancies in $\mathrm{P}_{3} 32$ and Ni aggregated supercells, at $300 \mathrm{~K}$ and $1200 \mathrm{~K}$. (d) Total energies of Ni aggregated supercells relative to the $\mathrm{P}_{3} 32$ phase. (Total energies of $\mathrm{Ni} / \mathrm{Mn}$ ordered supercells are set to $0 \mathrm{eV}$ ). One and two oxygen vacancies are equivalent to the chemical formulas of $\mathrm{LiNi}_{0.5} \mathrm{Mn}_{1.5} \mathrm{O}_{3.875}$ and $\mathrm{LiNi}_{0.5} \mathrm{Mn}_{1.5} \mathrm{O}_{3.750}$, respectively. Reproduced with permission from Ref. [45]. Copyright 2016 Elsevier.

Figure 3 (a) Thermogravimetric (TG) curve of $\mathrm{LiNi}_{0.5} \mathrm{Mn}_{1.5} \mathrm{O}_{4}$ spinel powder. The inset infrared spectrum shows the existence of adsorbed water prior to analysis. (b) FTIR spectra of ordered $\left(\mathrm{P}_{3} 32\right)$ and disordered $(\mathrm{Fd}-3 \mathrm{~m}) \mathrm{LiNi}_{0.5} \mathrm{Mn}_{1.5} \mathrm{O}_{4}$ as a function of synthesis temperature. The intensity ratio of two bands at 619 and $588 \mathrm{~cm}^{-1}$ can be used to qualitatively estimate percentage of ordering in spinel. (c) Room-temperature conductivities of $\mathrm{LiNi}_{0.5} \mathrm{Mn}_{1.5} \mathrm{O}_{4}$ pellets with respect to their lattice constants. (d) Dependence of activation energy of electron hopping on lattice constant of $\mathrm{LiNi}_{0.5} \mathrm{Mn}_{1.5} \mathrm{O}_{4}$. (e) Galvanostatic discharge curves of $\mathrm{LiNi}_{0.5} \mathrm{Mn}_{1.5} \mathrm{O}_{4}$. The percentage of capacity in the region of $\sim 4.0 \mathrm{~V}$ is also provided. (f) Cycling performance of $\mathrm{LiNi}_{0.5} \mathrm{Mn}_{1.5} \mathrm{O}_{4}$ prepared at different temperatures. (a, f) Reproduced with permission from Ref. [46]. Copyright 2006, The Electrochemical Society. (b-e) Reproduced with permission from Ref. [15]. Copyright 2006 American Chemical Society. 
Figure 4 (a) Relationship of cooling rate, lattice parameters and oxygen non-stoichiometry $\left(\mathrm{Mn}^{3+}\right.$ content) in $\mathrm{LiNi}_{0.5} \mathrm{Mn}_{1.5} \mathrm{O}_{4}$. (b, c) Electron diffraction patterns in the [100] zone of $\mathrm{LiNi}_{0.5} \mathrm{Mn}_{1.5} \mathrm{O}_{4}$ prepared with (b) $0.5{ }^{\circ} \mathrm{C} \mathrm{min}^{-1}$ and (c) $5{ }^{\circ} \mathrm{C} \mathrm{min}{ }^{-1}$ cooling rates. (d) Electrochemical performance of $\mathrm{LiNi}_{0.5} \mathrm{Mn}_{1.5} \mathrm{O}_{4}$ prepared with different cooling rates. (e, $\left.\mathrm{f}\right)$ Insitu XRD patterns of spinels at different states of charge and corresponding lattice parameter changes during $\mathrm{Li}^{+}$extraction for $\mathrm{LiNi}_{0.5} \mathrm{Mn}_{1.5} \mathrm{O}_{4}$ prepared with cooling rates of (e) $0.5{ }^{\circ} \mathrm{C} \mathrm{min}^{-1}$ and (f) $5{ }^{\circ} \mathrm{C} \min ^{-1}$. Reproduced with permission from Ref. [35]. Copyright 2012, The Royal Society of Chemistry.

Figure 5 (a) XRD patterns of " $\mathrm{LiNi}_{0.5} \mathrm{Mn}_{1.5} \mathrm{O}_{4-\delta}$ " powder samples prepared by reheating a C800 sample (prepared at $800^{\circ} \mathrm{C}$ and naturally cooled) and then quenching from $650^{\circ} \mathrm{C}(\mathrm{Q} 650), 800^{\circ} \mathrm{C}$ (Q800), $850^{\circ} \mathrm{C}(\mathrm{Q} 850)$, or $900^{\circ} \mathrm{C}$ (Q900). (b) TG curves in air of various " $\mathrm{LiNi}_{0.5} \mathrm{Mn}_{1.5} \mathrm{O}_{4-\delta}$ " samples. The inset shows heat/cool curves of a sample quenched at $900^{\circ} \mathrm{C}$. (c) Lattice parameter evolution of " $\mathrm{LiNi}_{0.5} \mathrm{Mn}_{1.5} \mathrm{O}_{4-\delta}$ " powder samples with oxygen stoichiometry. (d) Charge and discharge profiles of various powder samples (inset is cycling performance). Reproduced with permission from Ref. [47]. Copyright 2013 Elsevier.

Figure 6 (a) Variation of phase fractions with annealing times from XRD Rietveld refinement data based on the structural model with mixed disordered/ordered phases. (b) Comparison of voltage profiles of the various $\mathrm{LiNi}_{0.5} \mathrm{Mn}_{1.5} \mathrm{O}_{4}$ samples; recorded at third cycle with $\mathrm{C} / 10$ at $30^{\circ} \mathrm{C}$. (c) Effect of $700^{\circ} \mathrm{C}$ annealing time on the cycling performance $(\mathrm{C} / 10$ rate $)$ of $\mathrm{LiNi}_{0.5} \mathrm{Mn}_{1.5} \mathrm{O}_{4}$ at $30^{\circ} \mathrm{C}$. (d) Comparison of C-rate performance of $\mathrm{LiNi}_{0.5} \mathrm{Mn}_{1.5} \mathrm{O}_{4}$ with different annealing time. Reproduced with permission from Ref. [61]. Copyright 2014 American Chemical Society.

Figure 7 (a) TG curves for Ni-rich $\mathrm{LiNi}_{0.8} \mathrm{Mn}_{0.1} \mathrm{Co}_{0.1} \mathrm{O}_{2-\delta}$ samples heated and cooled sequentially in $\mathrm{O}_{2}$, air, and $\mathrm{N}_{2}$ atmospheres. (b) Oxygen content/non-stoichiometry as a function of temperature in different atmospheres. Reproduced with permission from Ref. [31]. Copyright 2012, The Electrochemical Society.

Figure 8 (a) Schematic illustration about the influence of oxygen defects on structural stability. (b) TG curves of $\mathrm{LiNi}_{0.8} \mathrm{Mn}_{0.1} \mathrm{Co}_{0.1} \mathrm{O}_{2}$ at different oxygen partial pressures. (c) High-resolution transmission electron microscope images, (d) Oxygen defect ratio and $\mathrm{Li} / \mathrm{Ni}$ cation mixing, (e) cycling performance at $1 \mathrm{C}$ rate between $2.8 \sim 4.3 \mathrm{~V}$ of $\mathrm{LiNi}_{0.8} \mathrm{Mn}_{0.1} \mathrm{Co}_{0.1} \mathrm{O}_{2}$ prepared at 
different oxygen partial pressures. Reproduced with permission from Ref. [69]. Copyright 2015 Elsevier.

Figure 9 (a, b) Ni 2 $\mathrm{p}_{3 / 2}$ X-ray photoelectron spectroscopy (XPS) spectral fitting for Ni-rich $\mathrm{LiNi}_{0.6} \mathrm{Mn}_{0.2} \mathrm{Co}_{0.2} \mathrm{O}_{2}$ prepared under different conditions: (a) 850_A (calcined in air at $850^{\circ} \mathrm{C}$ ) and (b) 850_O (calcined in $\mathrm{O}_{2}$ at $850^{\circ} \mathrm{C}$ ). (c) $\mathrm{Ni}^{3+} /\left(\mathrm{Ni}^{2+}+\mathrm{Ni}^{3+}\right)$ ratio as a function of sputtering depth for 850_A and 850_O. (d) Rate performance and (e) cycling performance of 850_A and 850_O tested at 1C rate. Reproduced with permission from Ref. [72]. Copyright 2016 Elsevier.

Figure 10 Calcination temperatures as a function of $\mathrm{Ni}$ content in $\mathrm{LiNi}_{\mathrm{x}} \mathrm{Mn}_{\mathrm{y}} \mathrm{Co}_{\mathrm{z}} \mathrm{O}_{2}$ materials, based on the data provided in Table 1 .

Figure 11 (a-c) Fitting results for Mn 2p XPS spectra of (a) quenched $\mathrm{Li}_{2} \mathrm{MnO}_{3}(\mathrm{QLMO})$, (b) $\mathrm{Li}_{2} \mathrm{MnO}_{3}$ milled with $5 \mathrm{wt} \%$ Super P (MLMO), and (c) annealed $\mathrm{Li}_{2} \mathrm{MnO}_{3}$ (ALMO). (d) dQ/dV profiles during initial charge of all three samples. (d) Discharge capacities as a function of cycle number in the voltage range of 2.0 4.8 V. Reproduced with permission from Ref. [33]. Copyright 2015 Elsevier.

Figure 12 (a) Scanning electron microscope images; (b) Ni 2p and (c) Mn 2p XPS spectra of $\mathrm{Li}\left[\mathrm{Li}_{0.2} \mathrm{Ni}_{0.2} \mathrm{Mn}_{0.6}\right] \mathrm{O}_{2-\delta}$ materials. (d) Charge/discharge profiles at $25 \mathrm{~mA} \mathrm{~g}^{-1}(\mathrm{C} / 10)$; (e) rate performance with inset showing electrochemical impedance spectra; (f) cycling performance at $\mathrm{C} / 3$ after three formation cycles at $\mathrm{C} / 10$ of $\mathrm{Li}\left[\mathrm{Li}_{0.2} \mathrm{Ni}_{0.2} \mathrm{Mn}_{0.6}\right] \mathrm{O}_{2-\delta}$ materials.

Figure 13 (a) Ion current vs. charging time and cell potential from mass spectrometry analysis of $\mathrm{O}_{2}$ evolved from charging $\mathrm{Li}\left[\mathrm{Li}_{0.2} \mathrm{Ni}_{0.2} \mathrm{Mn}_{0.6}\right] \mathrm{O}_{2}$. Reproduced with permission from Ref. [23]. Copyright 2006 American Chemical Society. (b) Spatially resolved O $K$ edge EEL spectra from the bulk to the surface of $\mathrm{Li}\left[\mathrm{Li}_{1 / 6} \mathrm{Ni}_{1 / 4} \mathrm{Mn}_{7 / 12}\right] \mathrm{O}_{2}$; (c) atomic configurations of $\mathrm{Li}\left[\mathrm{Li}_{1 / 6} \mathrm{Ni}_{1 / 4} \mathrm{Mn}_{7 / 12}\right] \mathrm{O}_{2}$; (d) oxygen vacancy formation energy vs. Li concentration. (b-d) Reproduced with permission from Ref. [112]. Copyright 2014, The Royal Society of Chemistry.

Figure 14 (a) In-situ XRD patterns combined with simultaneously measured mass spectroscopy data tracking the release of gaseous oxygen from charged $\mathrm{Li}_{x} \mathrm{Ni}_{0.5} \mathrm{Mn}_{1.5} \mathrm{O}_{4}$ during heating up to $375^{\circ} \mathrm{C}$. Reproduced with permission from Ref. [115]. Copyright 2014 American Chemical Society. (b) Correlation between discharge capacity, thermal stability, and capacity retention of 
$\mathrm{Li}\left[\mathrm{Ni}_{\mathrm{x}} \mathrm{Mn}_{\mathrm{y}} \mathrm{Co}_{\mathrm{z}}\right] \mathrm{O}_{2}(\mathrm{x}=1 / 3,0.5,0.6,0.7,0.8$, and 0.85). Reproduced with permission from Ref. [116]. Copyright 2013 Elsevier. (c) TG curves of LMR cathode $\mathrm{Li}_{1.167} \mathrm{Mn}_{0.5} \mathrm{Ni}_{0.167} \mathrm{Co}_{0.167} \mathrm{O}_{2}$ delithiated at various states of charge in the $1^{\text {st }}$ (dotted line) and $2^{\text {nd }}$ (solid line) cycles. Curves are shifted vertically by $5 \%$ each for easy comparison. Reproduced with permission from Ref. [119]. Copyright 2014 Elsevier.

Table 2 Synthesis conditions of $\mathrm{LiNi}_{\mathrm{x}} \mathrm{Mn}_{\mathrm{y}} \mathrm{Co}_{\mathrm{z}} \mathrm{O}_{2}$ with different Ni content

\begin{tabular}{|c|c|c|c|c|}
\hline Researchers & Particle size & Composition & Calcination temperature & $\begin{array}{l}\text { Calcination } \\
\text { atmosphere }\end{array}$ \\
\hline Sun et al. [124] & $\sim 10 \mu \mathrm{m}$ & $\begin{array}{l}\mathrm{LiNi}_{1-\mathrm{x}} \mathrm{Mn}_{\mathrm{x} / 2} \mathrm{Co}_{\mathrm{x} / 2} \mathrm{O}_{2} \\
(\mathrm{x}=0.1,0.05,0)\end{array}$ & $\begin{array}{r}x=0,650^{\circ} \mathrm{C}, 10 \mathrm{~h} \\
x=0.05,700^{\circ} \mathrm{C}, 10 \mathrm{~h} \\
x=0.1,750^{\circ} \mathrm{C}, 10 \mathrm{~h}\end{array}$ & $\mathrm{O}_{2}$ flow \\
\hline Cho et al. [125] & $\sim 10 \mu \mathrm{m}$ & $\mathrm{LiNi}_{0.8} \mathrm{Co}_{0.15} \mathrm{Al}_{0.05} \mathrm{O}_{2}$ & $750^{\circ} \mathrm{C}, 18 \mathrm{~h}$ & $\mathrm{O}_{2}$ flow \\
\hline Sun et al. [121] & $10 \sim 15 \mu \mathrm{m}$ & $\mathrm{LiNi}_{0.8} \mathrm{Mn}_{0.1} \mathrm{Co}_{0.1} \mathrm{O}_{2-\mathrm{z}} \mathrm{F}_{\mathrm{z}}$ & $770^{\circ} \mathrm{C}, 12 \mathrm{~h}$ & $\mathrm{O}_{2}$ flow \\
\hline Sun et al. [126] & $\sim 10 \mu \mathrm{m}$ & $\mathrm{LiNi}_{0.65} \mathrm{Mn}_{0.27} \mathrm{Co}_{0.08} \mathrm{O}_{2}$ & $840^{\circ} \mathrm{C}, 10 \mathrm{~h}$ & air \\
\hline Sun and Amine [19] & $\sim 10 \mu \mathrm{m}$ & $\begin{array}{l}\text { Concentration-gradient } \\
\mathrm{LiNi}_{0.64} \mathrm{Mn}_{0.18} \mathrm{Co}_{0.18} \mathrm{O}_{2}\end{array}$ & $780^{\circ} \mathrm{C}, 20 \mathrm{~h}$ & air \\
\hline Sun and Amine [18] & $\sim 10 \mu \mathrm{m}$ & $\begin{array}{l}\text { Concentration constant: } \\
\mathrm{LiNi}_{0.70} \mathrm{Mn}_{0.20} \mathrm{Co}_{0.10} \mathrm{O}_{2} \\
\text { Concentration-gradient: } \\
\mathrm{LiNi}_{0.75} \mathrm{Mn}_{0.15} \mathrm{Co}_{0.10} \mathrm{O}_{2}\end{array}$ & $750^{\circ} \mathrm{C}, 20 \mathrm{~h}$ & air \\
\hline Sun et al. [127] & $\sim 10 \mu \mathrm{m}$ & $\begin{array}{l}\mathrm{LiNi}_{0.8} \mathrm{Co}_{0.2} \mathrm{O}_{2} \\
\mathrm{LiNi}_{0.72} \mathrm{Mn}_{0.10} \mathrm{Co}_{0.18} \mathrm{O}_{2} \\
\mathrm{LiNi}_{0.55} \mathrm{Mn}_{0.30} \mathrm{Co}_{0.15} \mathrm{O}_{2}\end{array}$ & $\begin{array}{l}720^{\circ} \mathrm{C}, 20 \mathrm{~h} \\
750^{\circ} \mathrm{C}, 20 \mathrm{~h} \\
850^{\circ} \mathrm{C}, 15 \mathrm{~h}\end{array}$ & air \\
\hline Cho et al. [128] & $\sim 10 \mu \mathrm{m}$ & $\mathrm{LiNi}_{0.7} \mathrm{Mn}_{0.15} \mathrm{Co}_{0.15} \mathrm{O}_{2}$ & $800^{\circ} \mathrm{C}, 18 \mathrm{~h}$ & air \\
\hline Sun et al. [129] & $\sim 10 \mu \mathrm{m}$ & $\begin{array}{l}\mathrm{LiNi}_{0.58} \mathrm{Mn}_{0.14+\mathrm{x}} \mathrm{Co}_{0.28-\mathrm{x}} \mathrm{O}_{2} \\
(\mathrm{x}=0-0.14)\end{array}$ & $850^{\circ} \mathrm{C}, 20 \mathrm{~h}$ & air \\
\hline Sun et al. [130] & $5 \sim 8 \mu \mathrm{m}$ & $\begin{array}{l}\mathrm{LiNi}_{0.52} \mathrm{Mn}_{0.32-\mathrm{x}} \mathrm{Co}_{0.16+\mathrm{x}} \mathrm{O}_{2} \\
(\mathrm{x}=0,0.08,0.16)\end{array}$ & $820^{\circ} \mathrm{C}, 15 \mathrm{~h}$ & air \\
\hline Sun et al. [64] & $5 \sim 8 \mu \mathrm{m}$ & $\begin{array}{l}\mathrm{LiNi}_{0.6} \mathrm{Mn}_{0.2} \mathrm{Co}_{0.2} \mathrm{O}_{2} \\
\mathrm{LiNi}_{0.5} \mathrm{Mn}_{0.25} \mathrm{Co}_{0.25} \mathrm{O}_{2} \\
\mathrm{LiNi}_{0.4} \mathrm{Mn}_{0.3} \mathrm{Co}_{0.3} \mathrm{O}_{2}\end{array}$ & $\begin{array}{l}800^{\circ} \mathrm{C}, 15 \mathrm{~h} \\
850^{\circ} \mathrm{C}, 15 \mathrm{~h} \\
900^{\circ} \mathrm{C}, 15 \mathrm{~h}\end{array}$ & - \\
\hline
\end{tabular}




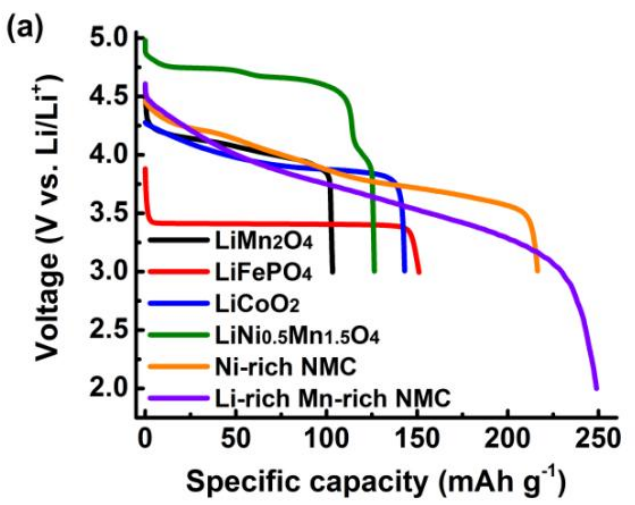

(b)

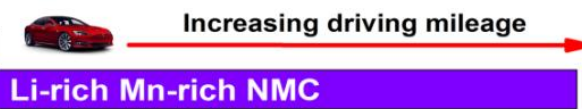

Ni-rich NMC

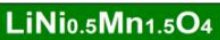

$\mathrm{LiCoO}_{2}$

$\mathrm{LiFePO}_{4}$

$\mathrm{LiMn}_{2} \mathrm{O}_{4}$
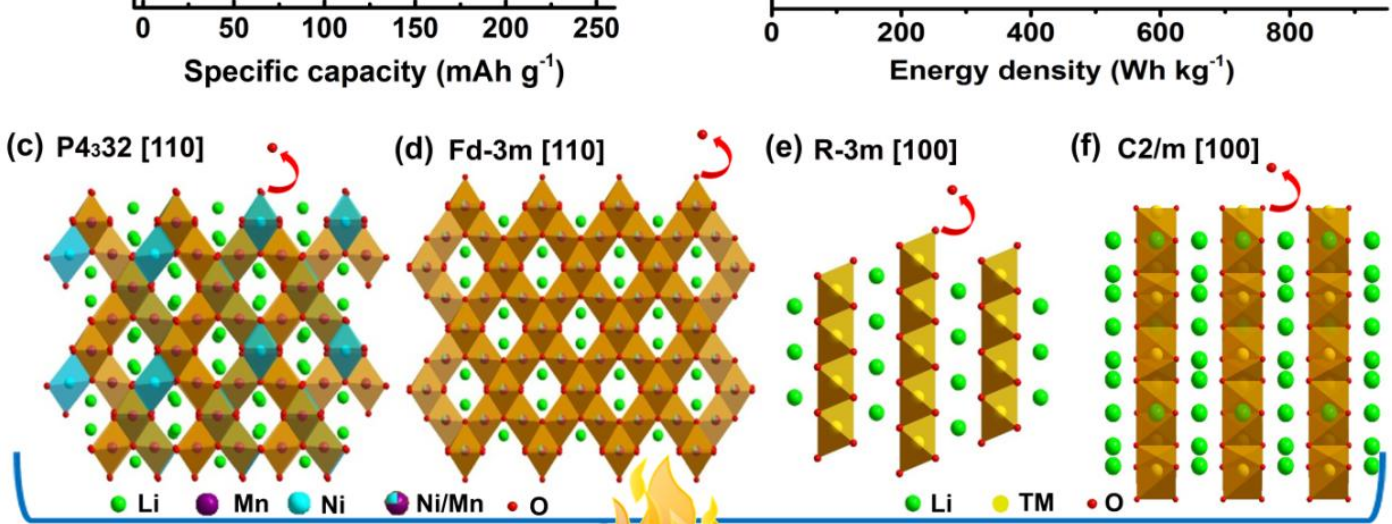

(e) R-3m [100]

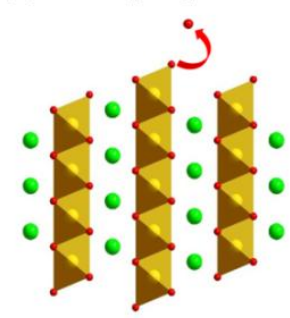

(f) $\mathrm{C} 2 / \mathrm{m}[100]$

$\mathrm{Mn} O \mathrm{Ni} O \mathrm{Ni} / \mathrm{Mn} \bullet \mathrm{O}$

- $\mathrm{Li}$ TM

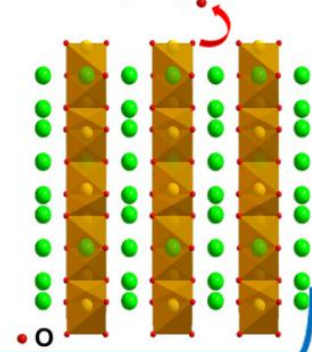

High temperature calcination

$\Rightarrow$ Oxygen non-stoichiometry

Figure 1 (a) Typical discharge voltage profiles of different cathode materials. (b) Energy density profiles of different cathode materials. (c-f) Atomic models showing the (c) ordered spinel structure with space group $\mathrm{P}_{3} 32$, (d) disordered spinel structure with space group Fd-3m, (e) layered structure with space group R-3m, and (f) monoclinic structure with space group $\mathrm{C} 2 / \mathrm{m}$. The fire represents the high temperature calcination process that leads to the formation of non-stoichiometry in the as-prepared materials. $\mathrm{TM}=$ transition metal. 
(a)

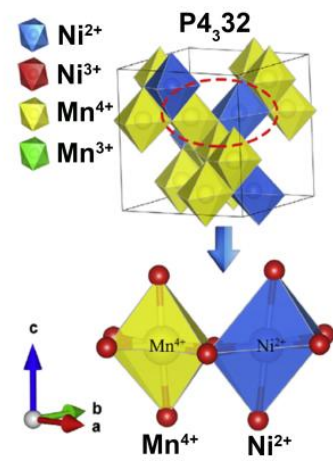

(c)

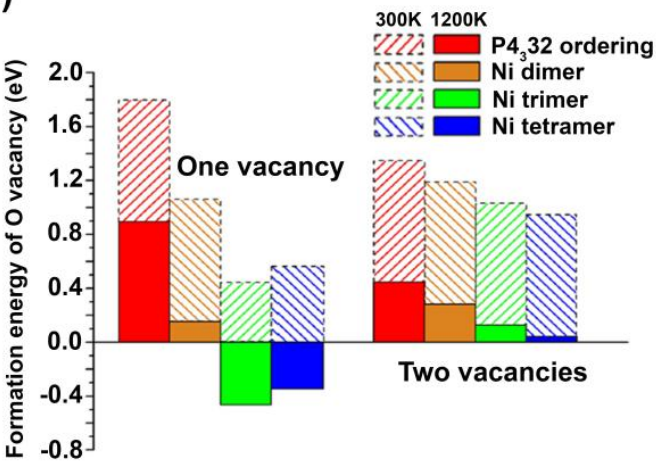

(b)
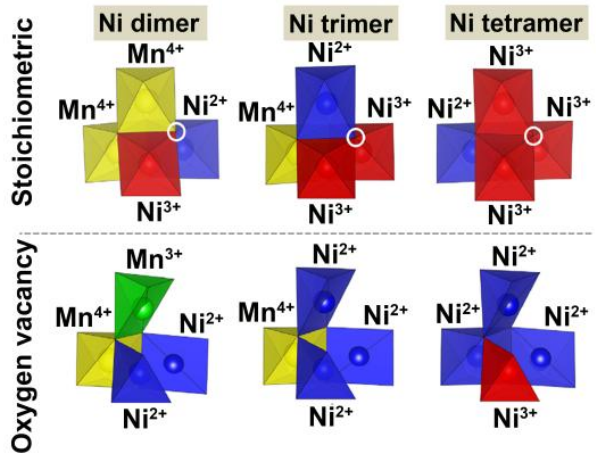

(d)

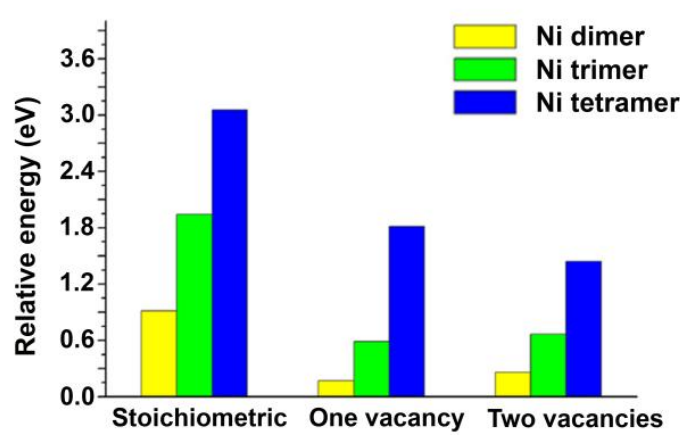

Figure 2 (a) The shapes of $\mathrm{Mn}(\mathrm{Ni}) \mathrm{O}_{6}$ octahedra in $\mathrm{P}_{3} 32$ and Ni-dimer supercells. (b) Local atomic structures of the most energetically favorable oxygen vacancy in Ni aggregated supercells. (c) Formation energies of one or two oxygen vacancies in $\mathrm{P}_{3} 32$ and Ni aggregated supercells, at $300 \mathrm{~K}$ and $1200 \mathrm{~K}$. (d) Total energies of Ni aggregated supercells relative to the $\mathrm{P}_{3} 32$ phase. (Total energies of $\mathrm{Ni} / \mathrm{Mn}$ ordered supercells are set to $0 \mathrm{eV}$ ). One and two oxygen vacancies are equivalent to the chemical formulas of $\mathrm{LiNi}_{0.5} \mathrm{Mn}_{1.5} \mathrm{O}_{3.875}$ and $\mathrm{LiNi}_{0.5} \mathrm{Mn}_{1.5} \mathrm{O}_{3.750}$, respectively. Reproduced with permission from Ref. [45]. Copyright 2016 Elsevier. 
(a)

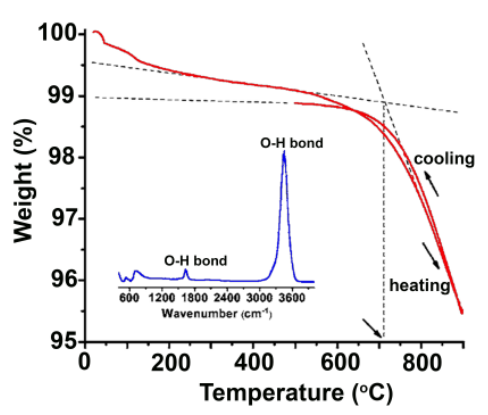

(d)

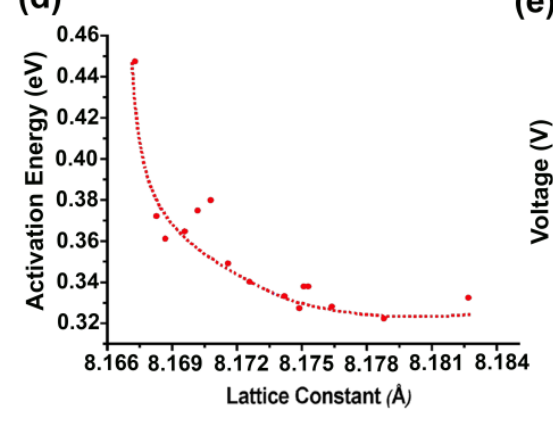

(b)

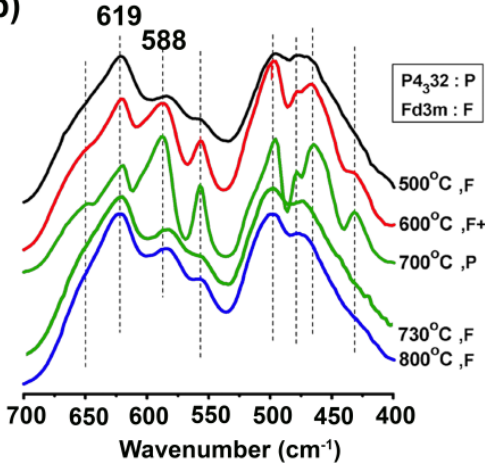

(e)

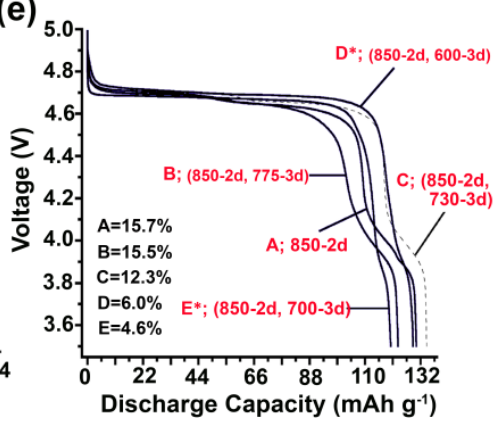

(c)

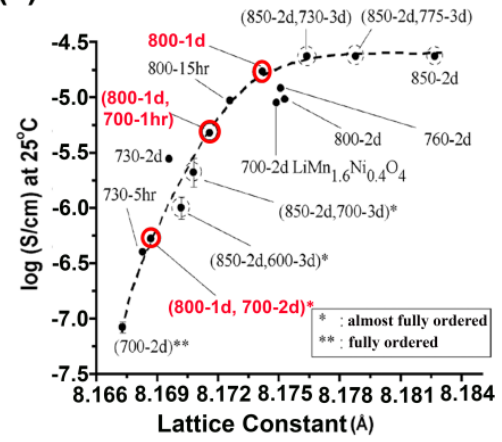

(f)

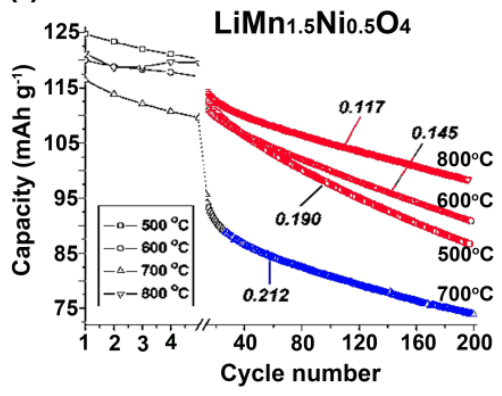

Figure 3 (a) Thermogravimetric (TG) curve of $\mathrm{LiNi}_{0.5} \mathrm{Mn}_{1.5} \mathrm{O}_{4}$ spinel powder. The inset infrared spectrum shows the existence of adsorbed water prior to analysis. (b) FTIR spectra of ordered $\left(\mathrm{P} 4_{3} 32\right)$ and disordered $(\mathrm{Fd}-3 \mathrm{~m}) \mathrm{LiNi}_{0.5} \mathrm{Mn}_{1.5} \mathrm{O}_{4}$ as a function of synthesis temperature. The intensity ratio of two bands at 619 and $588 \mathrm{~cm}^{-1}$ can be used to qualitatively estimate percentage of ordering in spinel. (c) Room-temperature conductivities of $\mathrm{LiNi}_{0.5} \mathrm{Mn}_{1.5} \mathrm{O}_{4}$ pellets with respect to their lattice constants. (d) Dependence of activation energy of electron hopping on lattice constant of $\mathrm{LiNi}_{0.5} \mathrm{Mn}_{1.5} \mathrm{O}_{4}$. (e) Galvanostatic discharge curves of $\mathrm{LiNi}_{0.5} \mathrm{Mn}_{1.5} \mathrm{O}_{4}$. The percentage of capacity in the region of $\sim 4.0 \mathrm{~V}$ is also provided. (f) Cycling performance of $\mathrm{LiNi}_{0.5} \mathrm{Mn}_{1.5} \mathrm{O}_{4}$ prepared at different temperatures. (a, f) Reproduced with permission from Ref. [46]. Copyright 2006, The Electrochemical Society. (b-e) Reproduced with permission from Ref. [15]. Copyright 2006 American Chemical Society. 
(a)

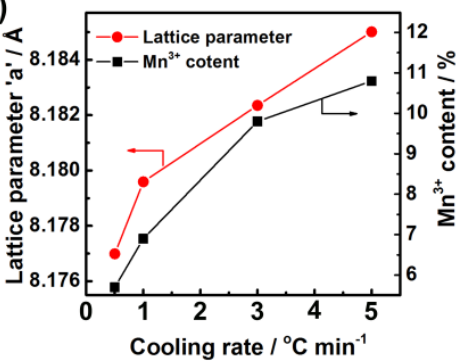

(d)
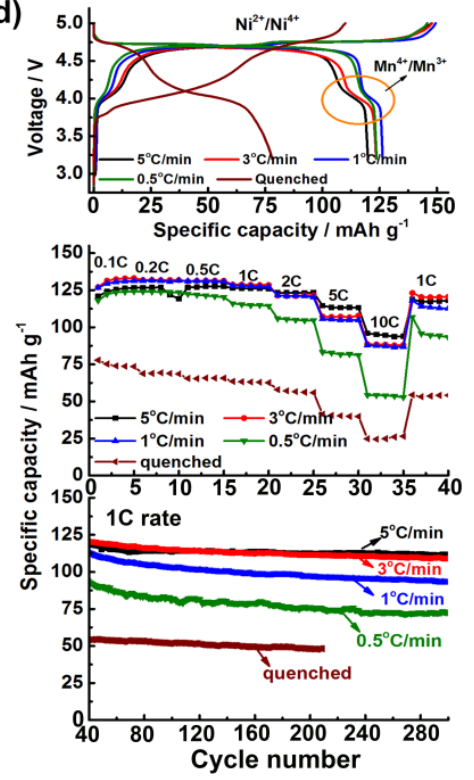

(b)

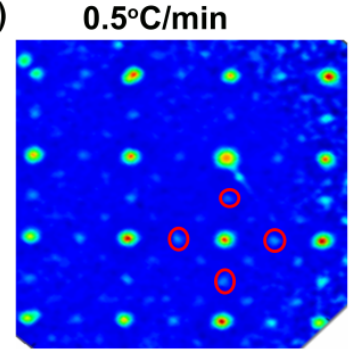

(e)

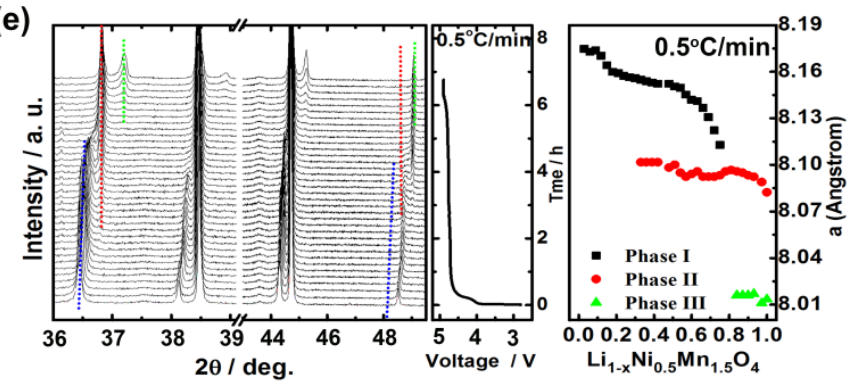

(f)

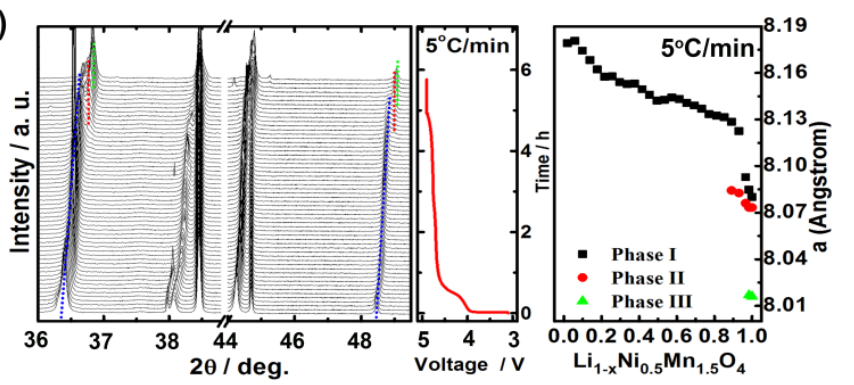

Figure 4 (a) Relationship of cooling rate, lattice parameters and oxygen non-stoichiometry $\left(\mathrm{Mn}^{3+}\right.$ content $)$ in $\mathrm{LiNi}_{0.5} \mathrm{Mn}_{1.5} \mathrm{O}_{4}$. (b, c) Electron diffraction patterns in the [100] zone of $\mathrm{LiNi}_{0.5} \mathrm{Mn}_{1.5} \mathrm{O}_{4}$ prepared with (b) $0.5^{\circ} \mathrm{C} \mathrm{min}^{-1}$ and (c) $5{ }^{\circ} \mathrm{C} \mathrm{min}{ }^{-1}$ cooling rates. (d) Electrochemical performance of $\mathrm{LiNi}_{0.5} \mathrm{Mn}_{1.5} \mathrm{O}_{4}$ prepared with different cooling rates. (e, $\mathrm{f}$ ) Insitu XRD patterns of spinels at different states of charge and corresponding lattice parameter changes during $\mathrm{Li}^{+}$extraction for $\mathrm{LiNi}_{0.5} \mathrm{Mn}_{1.5} \mathrm{O}_{4}$ prepared with cooling rates of (e) $0.5{ }^{\circ} \mathrm{C} \mathrm{min}^{-1}$ and (f) $5{ }^{\circ} \mathrm{C} \min ^{-1}$. Reproduced with permission from Ref. [35]. Copyright 2012, The Royal Society of Chemistry. 

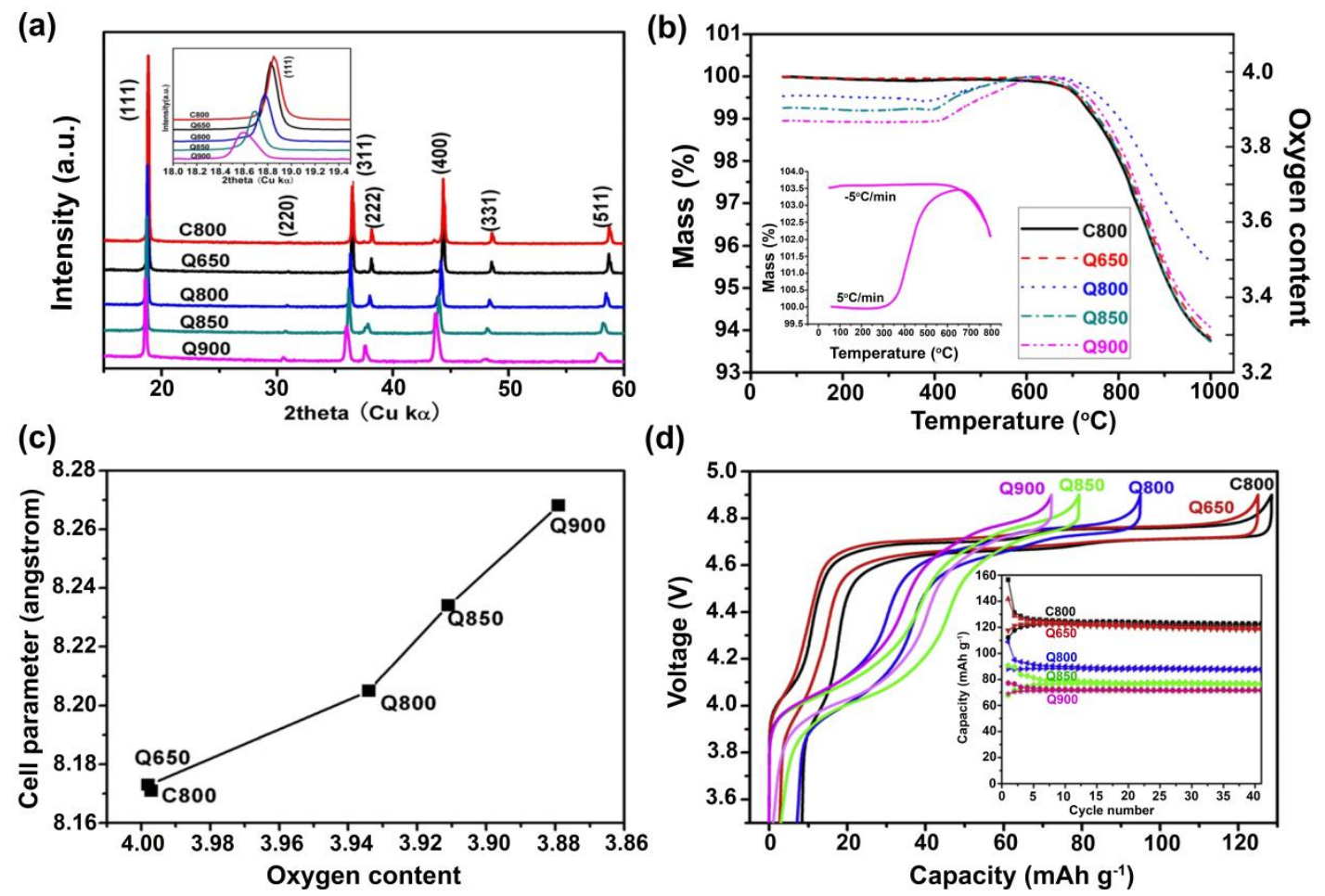

Figure 5 (a) XRD patterns of " $\mathrm{LiNi}_{0.5} \mathrm{Mn}_{1.5} \mathrm{O}_{4-\delta}$ " powder samples prepared by reheating a $\mathrm{C} 800$ sample (prepared at $800^{\circ} \mathrm{C}$ and naturally cooled) and then quenching from $650^{\circ} \mathrm{C}(\mathrm{Q} 650), 800^{\circ} \mathrm{C}$ (Q800), $850^{\circ} \mathrm{C}(\mathrm{Q} 850)$, or $900^{\circ} \mathrm{C}$ (Q900). (b) TG curves in air of various “ $\mathrm{LiNi}_{0.5} \mathrm{Mn}_{1.5} \mathrm{O}_{4-\delta}$ " samples. The inset shows heat/cool curves of a sample quenched at $900^{\circ} \mathrm{C}$. (c) Lattice parameter

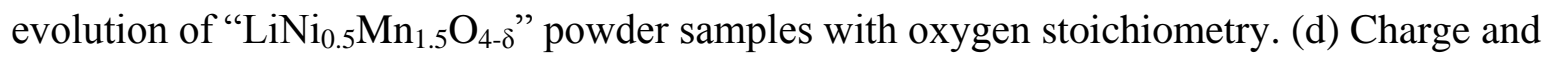
discharge profiles of various powder samples (inset is cycling performance). Reproduced with permission from Ref. [47]. Copyright 2013 Elsevier. 
(a)

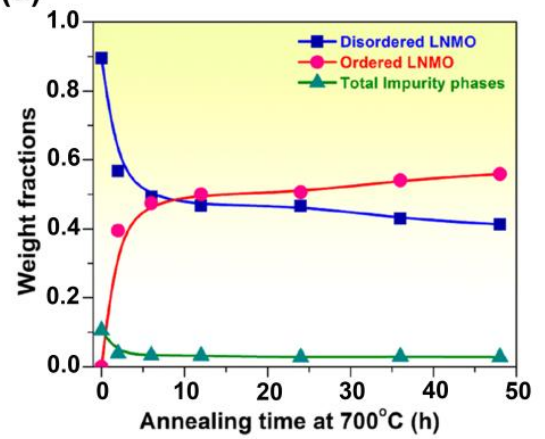

(c)

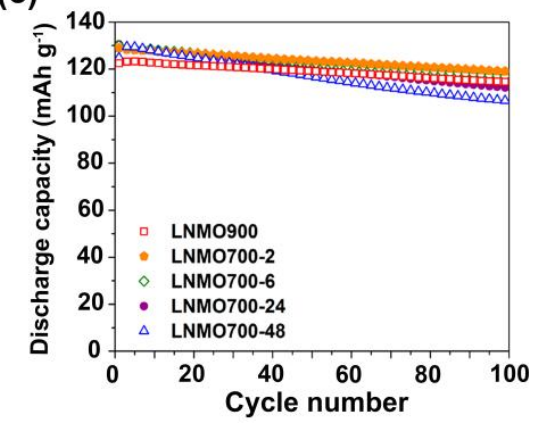

(b)

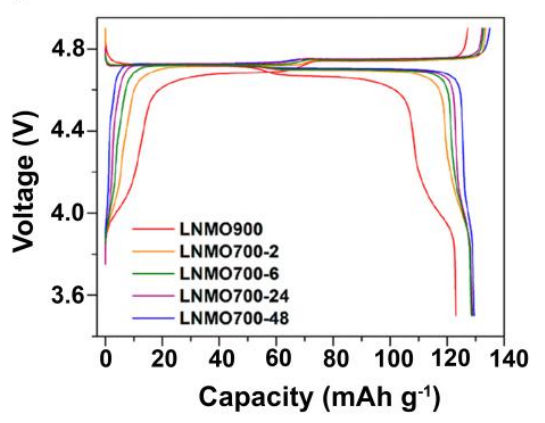

(d)

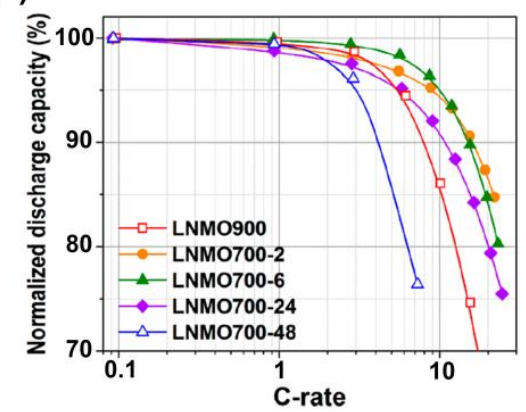

Figure 6 (a) Variation of phase fractions with annealing times from XRD Rietveld refinement data based on the structural model with mixed disordered/ordered phases. (b) Comparison of voltage profiles of the various $\mathrm{LiNi}_{0.5} \mathrm{Mn}_{1.5} \mathrm{O}_{4}$ samples; recorded at third cycle with $\mathrm{C} / 10$ at $30^{\circ} \mathrm{C}$.

(c) Effect of $700^{\circ} \mathrm{C}$ annealing time on the cycling performance $(\mathrm{C} / 10$ rate $)$ of $\mathrm{LiNi}_{0.5} \mathrm{Mn}_{1.5} \mathrm{O}_{4}$ at $30^{\circ} \mathrm{C}$. (d) Comparison of C-rate performance of $\mathrm{LiNi}_{0.5} \mathrm{Mn}_{1.5} \mathrm{O}_{4}$ with different annealing time. Reproduced with permission from Ref. [61]. Copyright 2014 American Chemical Society. 

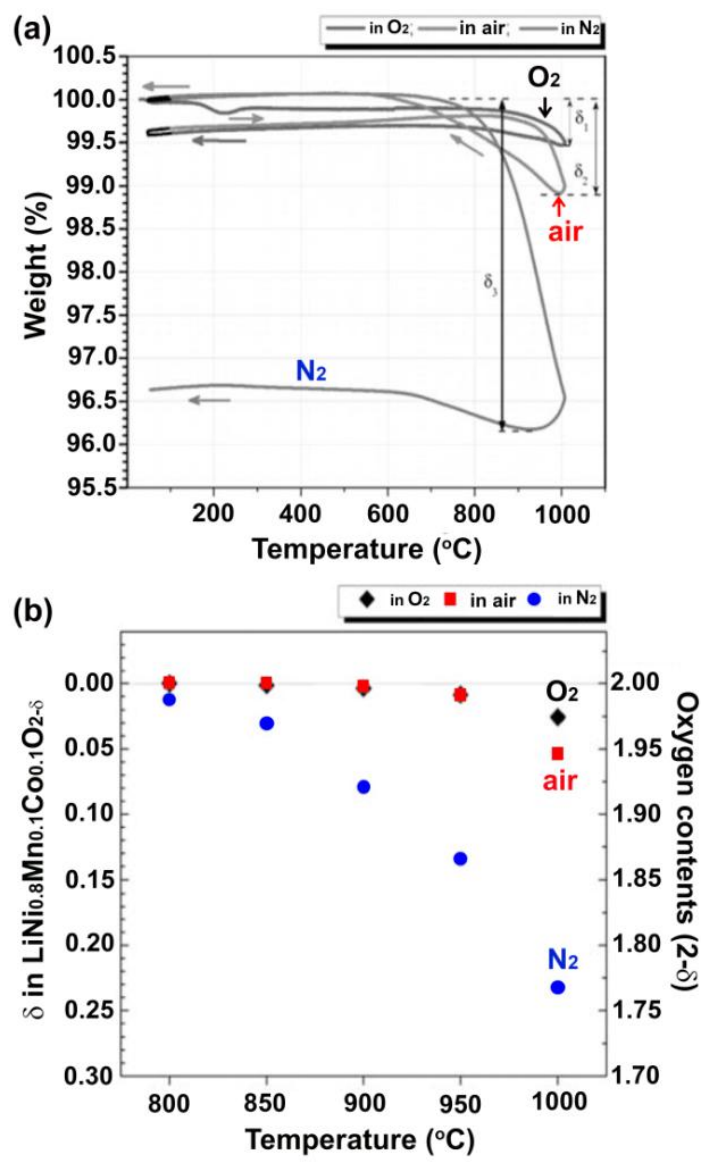

Figure 7 (a) TG curves for Ni-rich $\mathrm{LiNi}_{0.8} \mathrm{Mn}_{0.1} \mathrm{Co}_{0.1} \mathrm{O}_{2-\delta}$ samples heated and cooled sequentially in $\mathrm{O}_{2}$, air, and $\mathrm{N}_{2}$ atmospheres. (b) Oxygen content/non-stoichiometry as a function of temperature in different atmospheres. Reproduced with permission from Ref. [31]. Copyright 2012, The Electrochemical Society. 


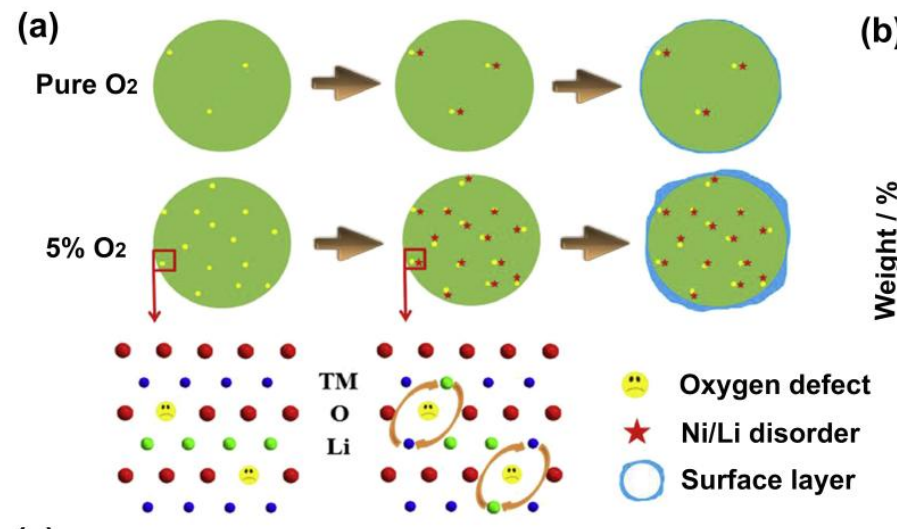

(c)
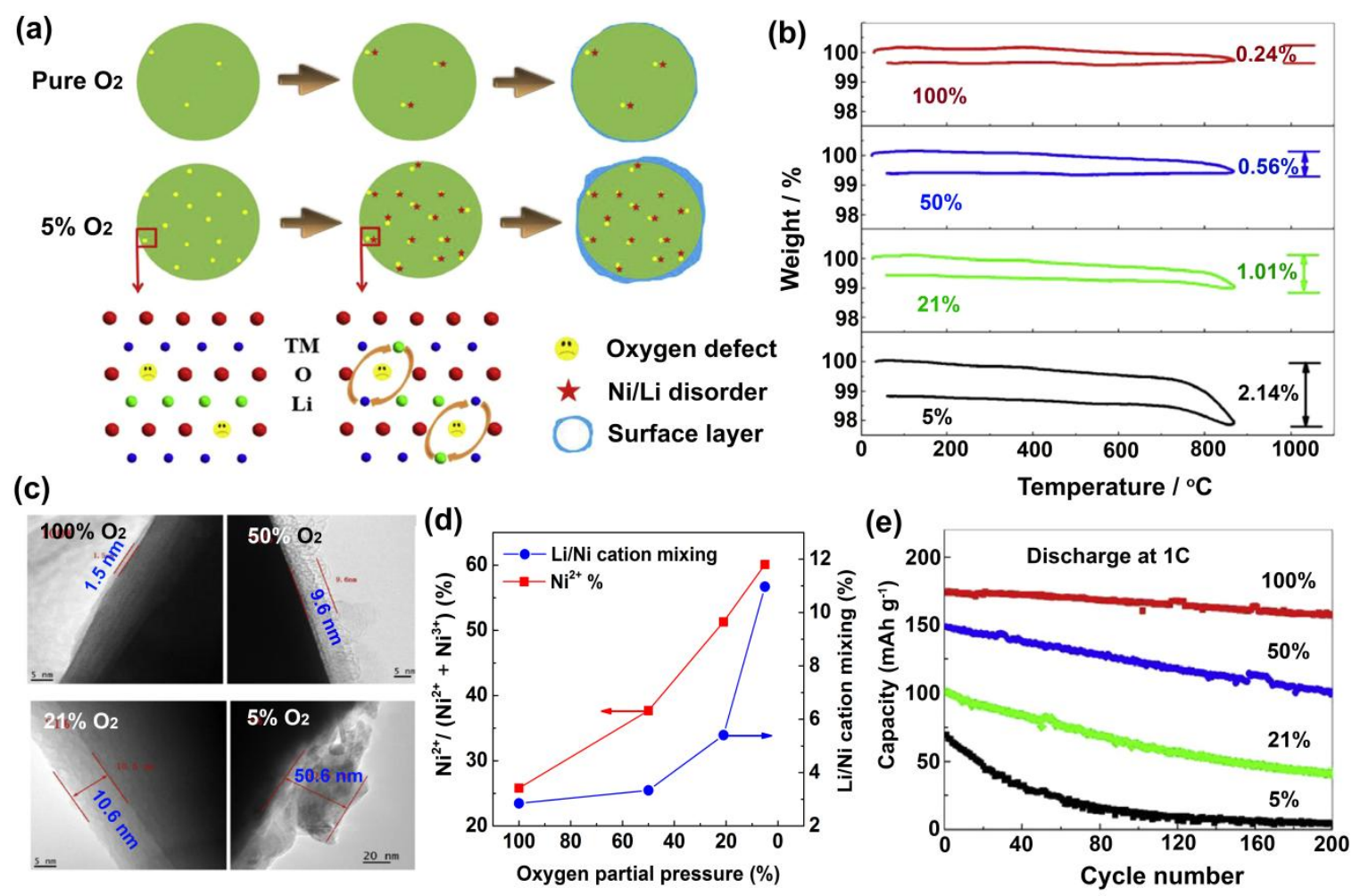

Figure 8 (a) Schematic illustration about the influence of oxygen defects on structural stability.

(b) TG curves of $\mathrm{LiNi}_{0.8} \mathrm{Mn}_{0.1} \mathrm{Co}_{0.1} \mathrm{O}_{2}$ at different oxygen partial pressures. (c) High-resolution transmission electron microscope images, (d) Oxygen defect ratio and $\mathrm{Li} / \mathrm{Ni}$ cation mixing, (e) cycling performance at $1 \mathrm{C}$ rate between $2.8 \sim 4.3 \mathrm{~V}$ of $\mathrm{LiNi}_{0.8} \mathrm{Mn}_{0.1} \mathrm{Co}_{0.1} \mathrm{O}_{2}$ prepared at different oxygen partial pressures. Reproduced with permission from Ref. [69]. Copyright 2015 Elsevier. 


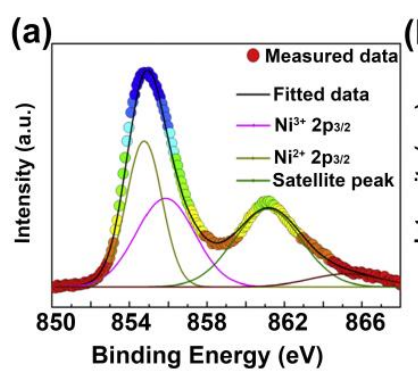

(d)

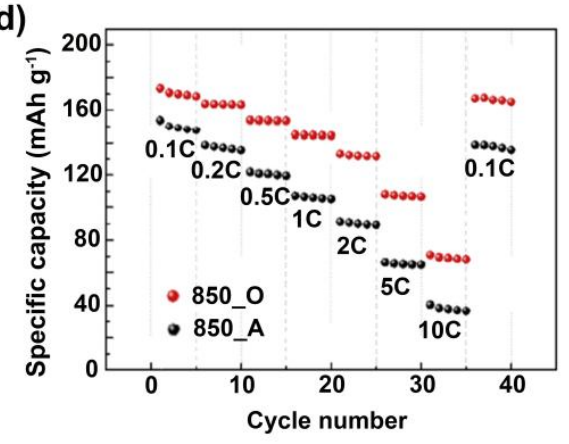

(c)
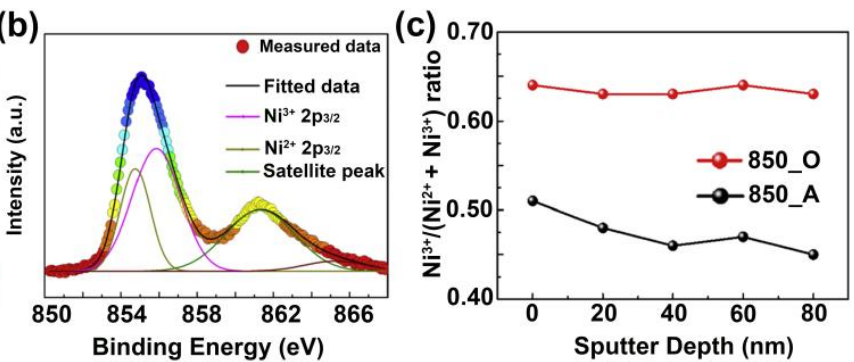

(e)

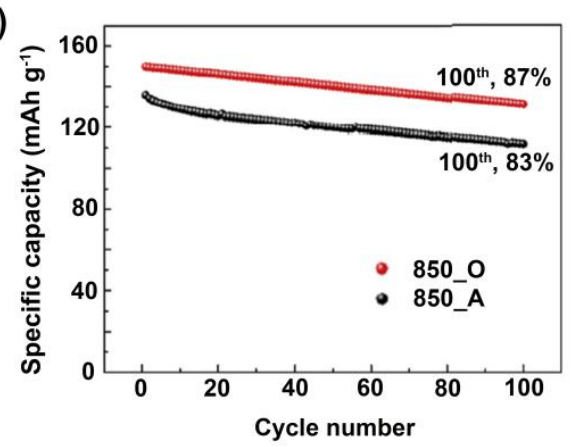

Figure $9(\mathrm{a}, \mathrm{b}) \mathrm{Ni} 2 \mathrm{p}_{3 / 2} \mathrm{X}$-ray photoelectron spectroscopy (XPS) spectral fitting for Ni-rich $\mathrm{LiNi}_{0.6} \mathrm{Mn}_{0.2} \mathrm{Co}_{0.2} \mathrm{O}_{2}$ prepared under different conditions: (a) 850_A (calcined in air at $850^{\circ} \mathrm{C}$ ) and (b) 850_O (calcined in $\mathrm{O}_{2}$ at $\left.850^{\circ} \mathrm{C}\right)$. (c) $\mathrm{Ni}^{3+} /\left(\mathrm{Ni}^{2+}+\mathrm{Ni}^{3+}\right)$ ratio as a function of sputtering depth for 850_A and 850_O. (d) Rate performance and (e) cycling performance of 850_A and 850_O tested at 1C rate. Reproduced with permission from Ref. [72]. Copyright 2016 Elsevier. 


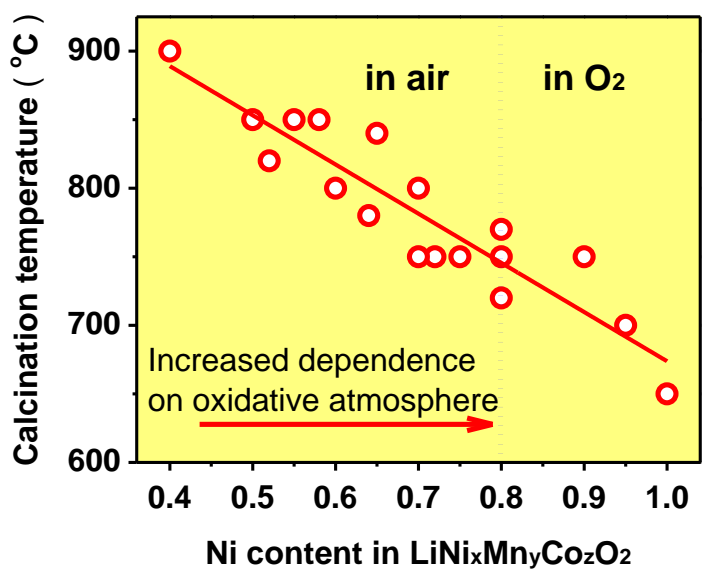

Figure 10 Calcination temperatures as a function of $\mathrm{Ni}$ content in $\mathrm{LiNi}_{\mathrm{x}} \mathrm{Mn}_{\mathrm{y}} \mathrm{Co}_{\mathrm{z}} \mathrm{O}_{2}$ materials, based on the data provided in Table 1. 
(a)

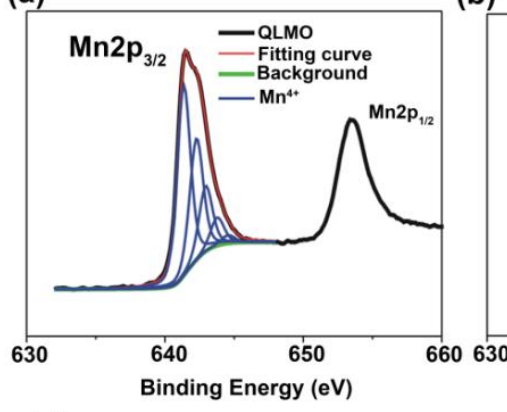

(d)

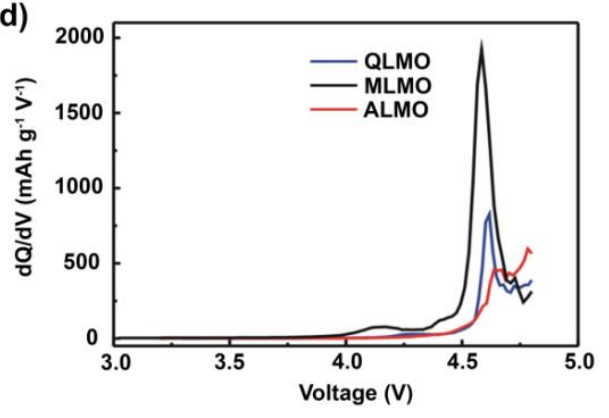

(c)

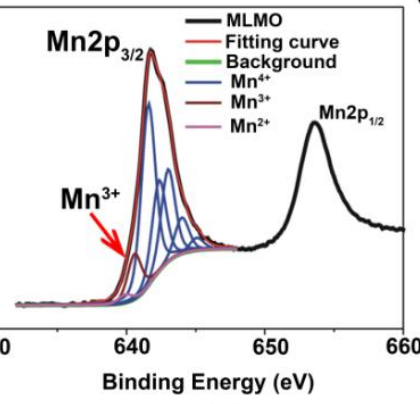

(e)

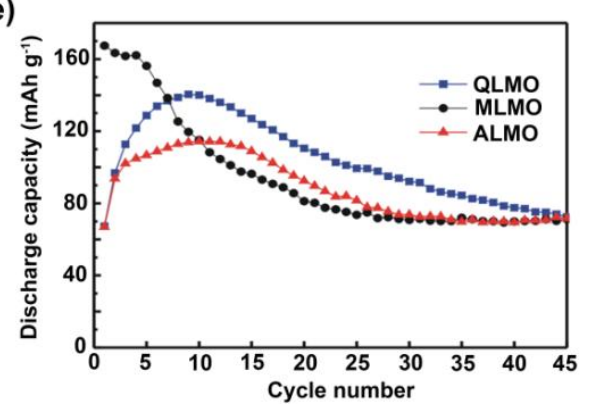

Figure 11 (a-c) Fitting results for Mn 2p XPS spectra of (a) quenched $\mathrm{Li}_{2} \mathrm{MnO}_{3}$ (QLMO), (b) $\mathrm{Li}_{2} \mathrm{MnO}_{3}$ milled with 5 wt $\%$ Super P (MLMO), and (c) annealed $\mathrm{Li}_{2} \mathrm{MnO}_{3}$ (ALMO). (d) dQ/dV profiles during initial charge of all three samples. (d) Discharge capacities as a function of cycle number in the voltage range of 2.0 4.8 V. Reproduced with permission from Ref. [33]. Copyright 2015 Elsevier. 
(a)
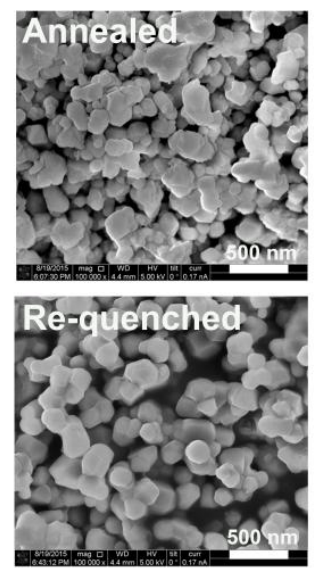

(d)

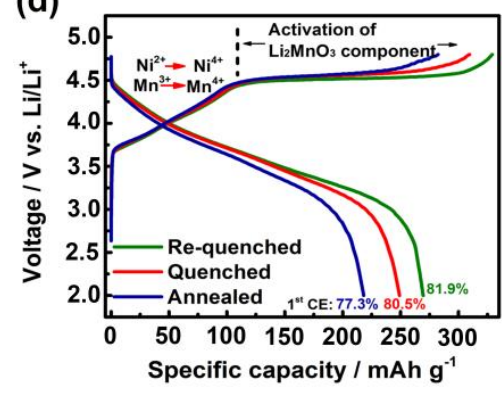

(b)

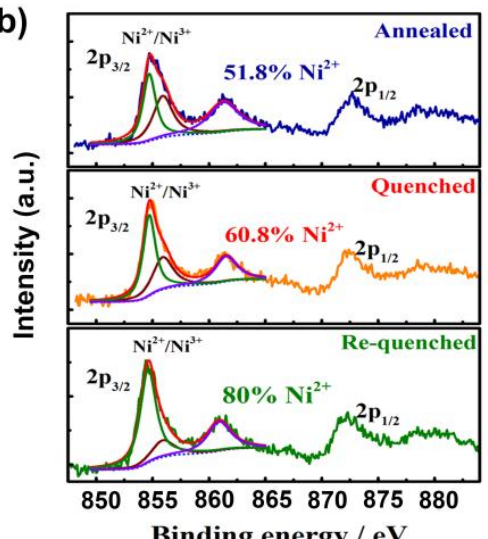

Binding energy / eV

(e)

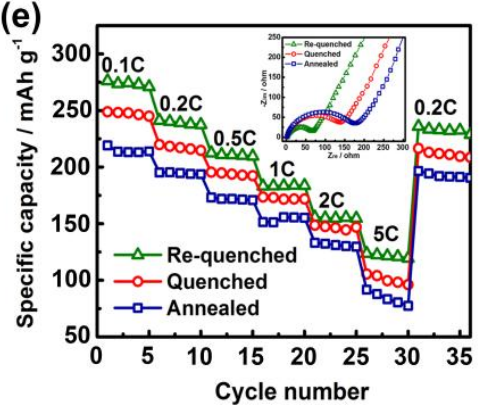

(c)

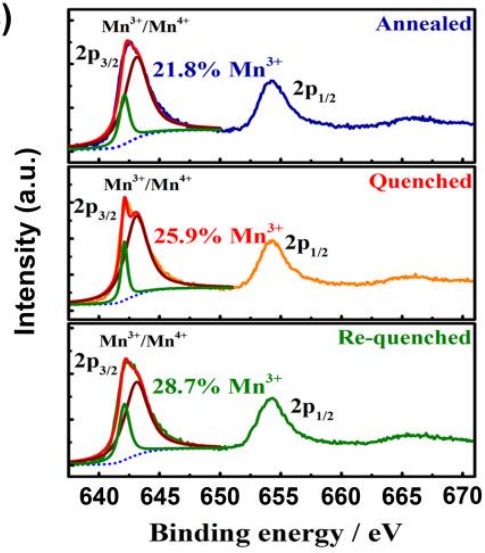

(f)

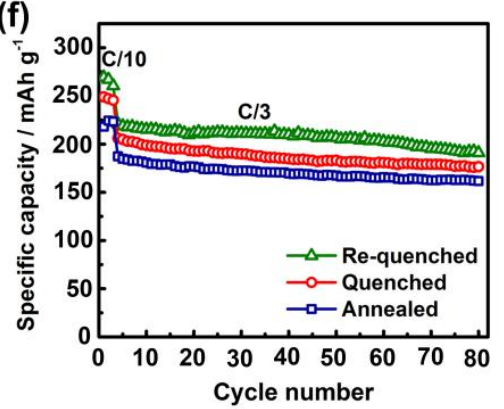

Figure 12 (a) Scanning electron microscope images; (b) Ni 2p and (c) Mn 2p XPS spectra of $\mathrm{Li}\left[\mathrm{Li}_{0.2} \mathrm{Ni}_{0.2} \mathrm{Mn}_{0.6}\right] \mathrm{O}_{2-\delta}$ materials. (d) Charge/discharge profiles at $25 \mathrm{~mA} \mathrm{~g}^{-1}$ (C/10); (e) rate performance with inset showing electrochemical impedance spectra; (f) cycling performance at $\mathrm{C} / 3$ after three formation cycles at $\mathrm{C} / 10$ of $\mathrm{Li}\left[\mathrm{Li}_{0.2} \mathrm{Ni}_{0.2} \mathrm{Mn}_{0.6}\right] \mathrm{O}_{2-\delta}$ materials. 


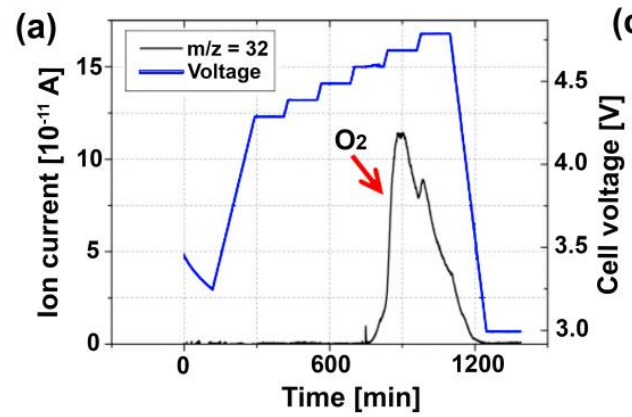

(b)
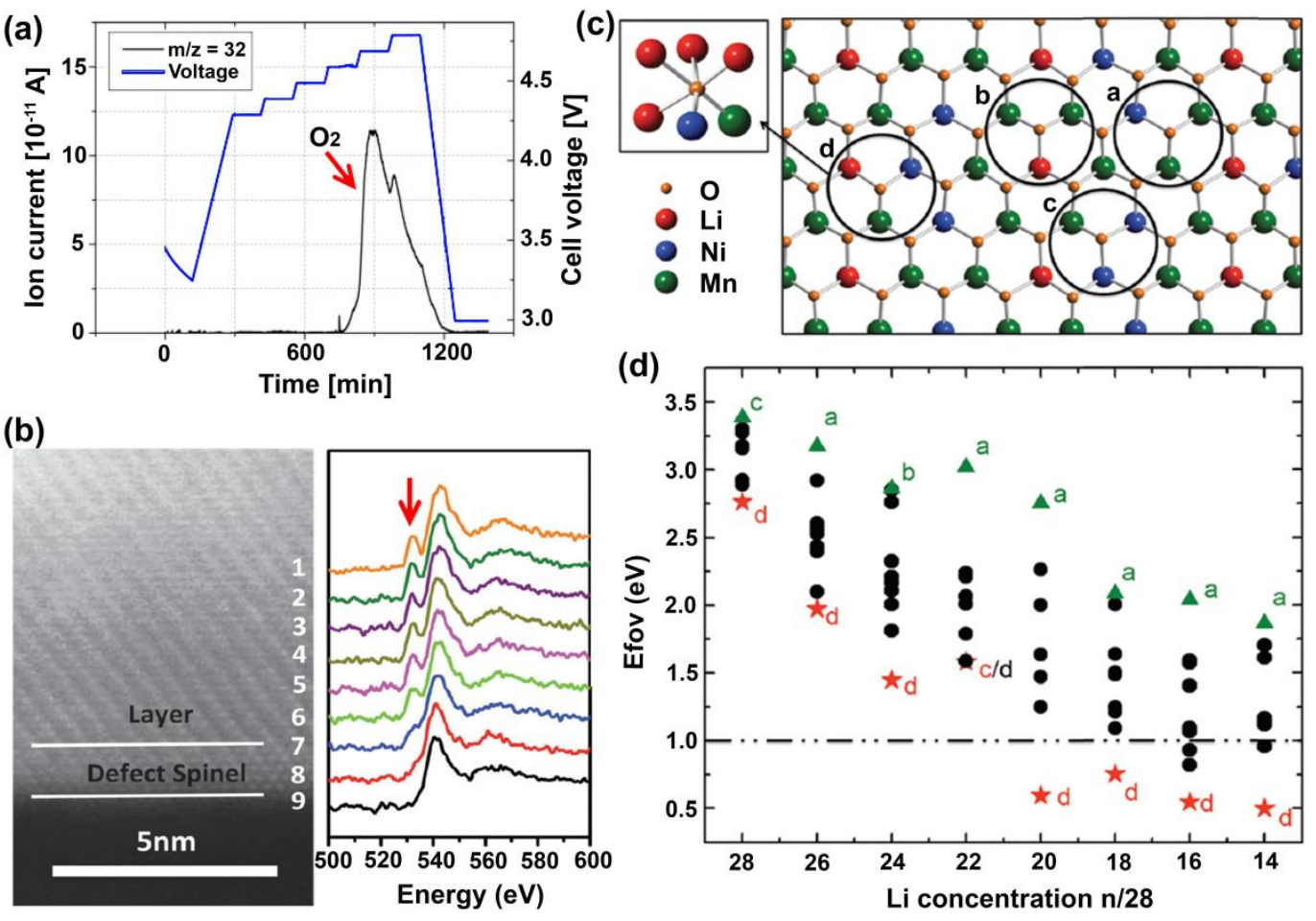

(d)

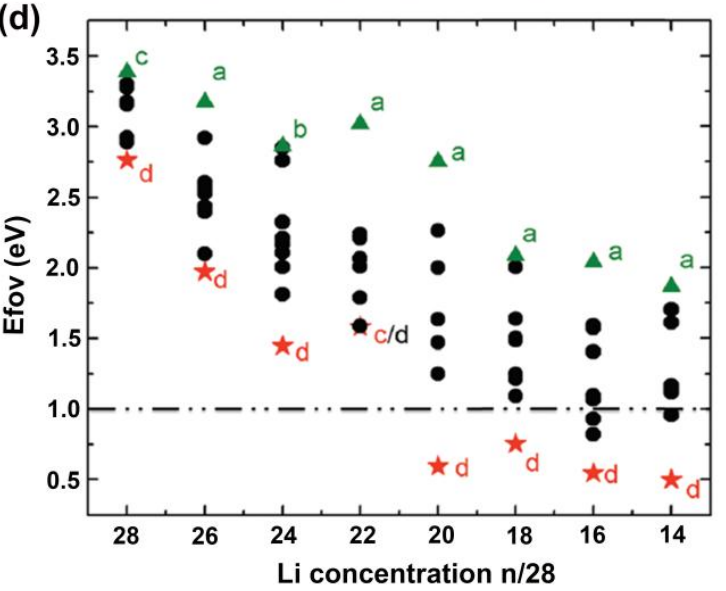

Figure 13 (a) Ion current vs. charging time and cell potential from mass spectrometry analysis of $\mathrm{O}_{2}$ evolved from charging $\mathrm{Li}\left[\mathrm{Li}_{0.2} \mathrm{Ni}_{0.2} \mathrm{Mn}_{0.6}\right] \mathrm{O}_{2}$. Reproduced with permission from Ref. [23]. Copyright 2006 American Chemical Society. (b) Spatially resolved O $K$ edge EEL spectra from the bulk to the surface of $\mathrm{Li}\left[\mathrm{Li}_{1 / 6} \mathrm{Ni}_{1 / 4} \mathrm{Mn}_{7 / 12}\right] \mathrm{O}_{2}$; (c) atomic configurations of $\mathrm{Li}\left[\mathrm{Li}_{1 / 6} \mathrm{Ni}_{1 / 4} \mathrm{Mn}_{7 / 12}\right] \mathrm{O}_{2} ;$ (d) oxygen vacancy formation energy vs. Li concentration. (b-d) Reproduced with permission from Ref. [112]. Copyright 2014, The Royal Society of Chemistry. 

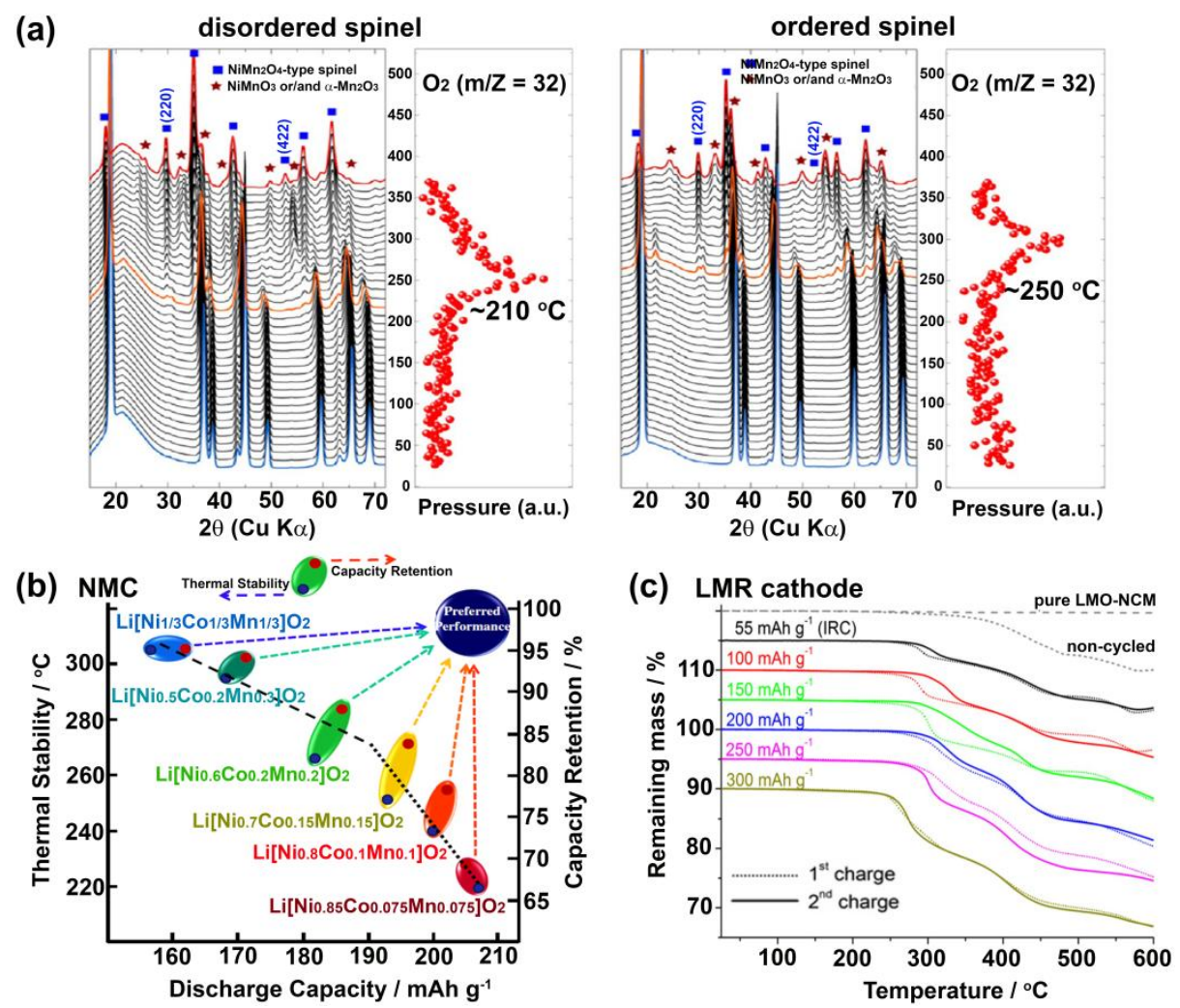

Figure 14 (a) In-situ XRD patterns combined with simultaneously measured mass spectroscopy data tracking the release of gaseous oxygen from charged $\mathrm{Li}_{x} \mathrm{Ni}_{0.5} \mathrm{Mn}_{1.5} \mathrm{O}_{4}$ during heating up to $375^{\circ} \mathrm{C}$. Reproduced with permission from Ref. [115]. Copyright 2014 American Chemical Society. (b) Correlation between discharge capacity, thermal stability, and capacity retention of $\mathrm{Li}\left[\mathrm{Ni}_{\mathrm{x}} \mathrm{Mn}_{\mathrm{y}} \mathrm{Co}_{z}\right] \mathrm{O}_{2}(\mathrm{x}=1 / 3,0.5,0.6,0.7,0.8$, and 0.85$)$. Reproduced with permission from Ref. [116]. Copyright 2013 Elsevier. (c) TG curves of LMR cathode $\mathrm{Li}_{1.167} \mathrm{Mn}_{0.5} \mathrm{Ni}_{0.167} \mathrm{Co}_{0.167} \mathrm{O}_{2}$ delithiated at various states of charge in the $1^{\text {st }}$ (dotted line) and $2^{\text {nd }}$ (solid line) cycles. Curves are shifted vertically by 5\% each for easy comparison. Reproduced with permission from Ref. [119]. Copyright 2014 Elsevier. 


\section{TOC Graphic}

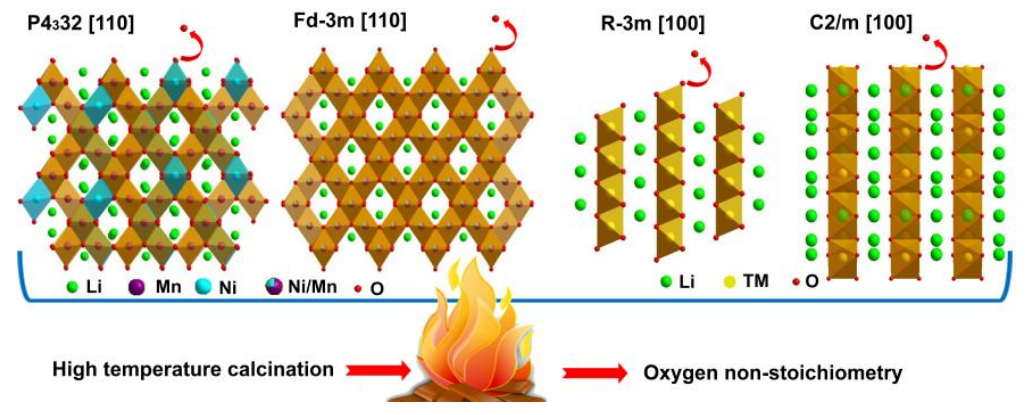




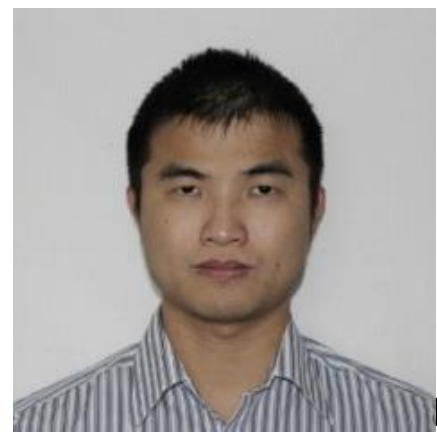

Dr. Jianming Zheng is currently a staff scientist of the Pacific Northwest National Laboratory. Dr. Zheng has expertise and extensive experience in the development of high-energy-density cathode materials for Li-ion batteries, the development of high performance electrolytes/additives for Li-ion batteries, and the protection of Li metal anode for rechargeable Li metal batteries. He also has expertise in the development of high-energy and long cycle life Li-S batteries, and the development of layered structure cathode materials for sodium ion batteries. Dr. Zheng has more than 60 papers published in peer-reviewed professional journals, and holds 4 patents pending.

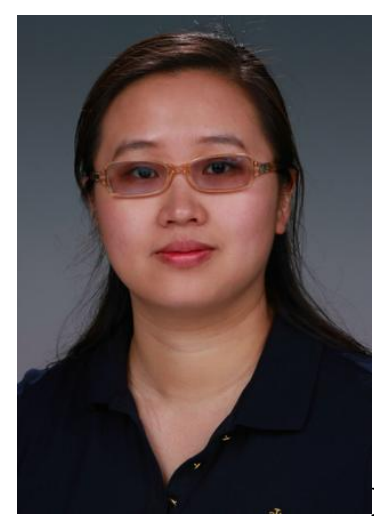

Dr. Jie Xiao is an associate professor at Department of Chemistry \& Biochemistry at University of Arkansas. Before that, she was a senior staff scientist at Pacific Northwest National Laboratory (PNNL). Dr. Xiao has been working in the energy research field for more than ten years and has extensive experiences in various battery technologies. She is the recipient of several awards including Ronald L. Brodzinski Early Career Exceptional Achievement Award and R\&D 100 award etc. Dr. Xiao has published more than 80 peerreviewed journal papers, 2 book chapters and 17 US patents (issued and pending) in the energy storage area. 


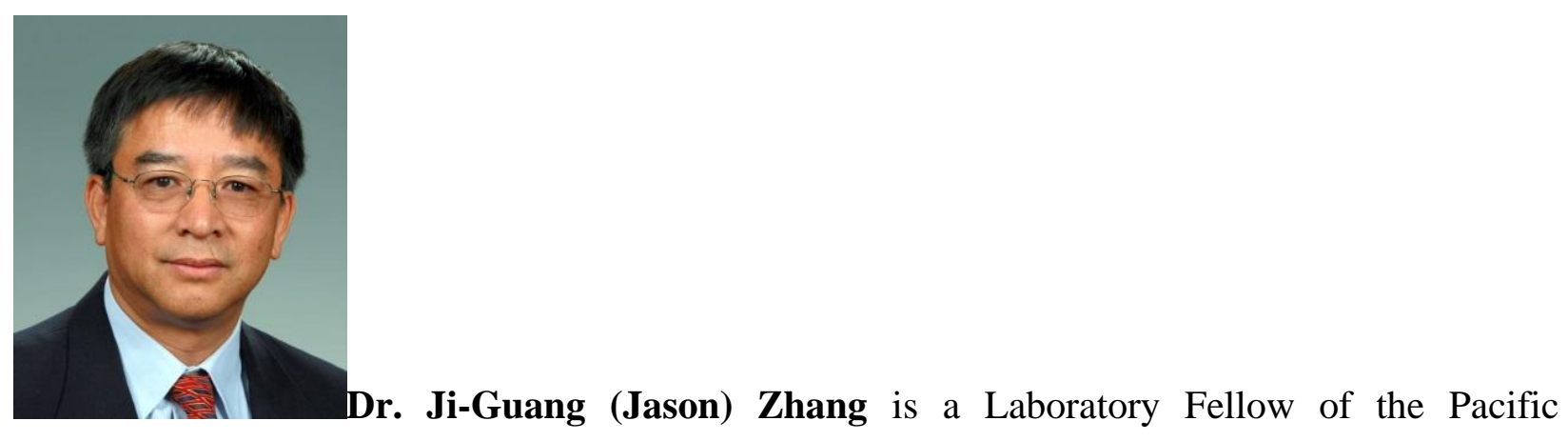
Northwest National Laboratory. He is the group leader for PNNL's efforts in energy storage for transportation applications and has 25-year experience in the development of energy storage devices, including Li-ion batteries, Li-air batteries, Li-metal batteries, Li-S batteries, and thinfilm solid-state batteries. He was the co-recipient of two R\&D 100 awards, holds 17 patents and publishes more than 200 papers in refereed journals. He was named Thomson Reuters' Highly Cited Researchers-2015 in Engineering category. 
Graphical Abstract

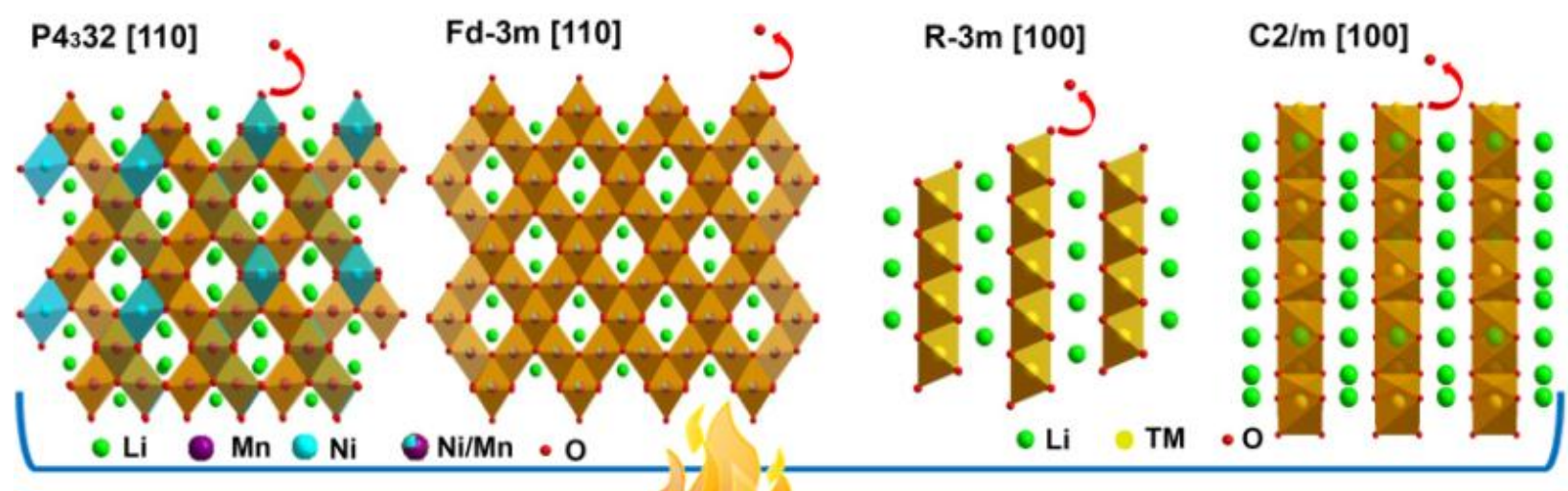

High temperature calcination $\Rightarrow$ Oxygen non-stoichiometry 